\title{
Export market risk and the role of state credit guarantees
}

\author{
Inga Heiland ${ }^{1,2,3} \cdot$ Erdal Yalcin $^{2,4,5}$
}

Published online: 2 June 2020

(C) The Author(s) 2021, corrected publication 2021

\begin{abstract}
Many countries offer state credit guarantees to support credit-constrained exporters. The policy instrument is commonly justified by governments as a means to mitigating adverse outcomes of financial market frictions for exporting firms. Accumulated returns to the German state credit guarantee scheme deriving from risk-compensating premia have outweighed accumulated losses over the past 60 years. Why do private financial agents not step in and provide insurance given that the state-run program yields positive returns? We argue that costs of risk diversification, liquidity management, and coordination among creditors limit the ability of private financial agents to offer comparable insurance products. Moreover, we suggest that the government's greater effectiveness in recovering claims in foreign countries endows the state with a cost advantage in dealing with the risks involved in large export projects. We test these hypotheses using monthly firm-level data combined with official transactionlevel data on covered exports of German firms and find suggestive evidence that positive effects on trade are due to mitigated financial constraints: State credit guarantees benefit firms that are dependent on external finance, if the value at risk which they seek to cover is large, and at times when refinancing conditions on the private financial market are tight.
\end{abstract}

Keywords State export credit guarantees $\cdot$ Credit constraints $\cdot$ Financial frictions

Erdal Yalcin

erdal.yalcin@htwg-konstanz.de

Inga Heiland

inga.heiland@econ.uio.no

1 Department of Economics, University of Oslo, Moltke Moes Vei 31, 0831 Oslo, Norway

2 CESifo, Munich, Germany

3 CEPR, London, UK

4 HTWG Konstanz, University of Applied Sciences, Alfred-Wachtel-Str. 8, 78462 Konstanz, Germany

5 Tuborg Research Centre for Globalisation and Firm, Aarhus, Denmark 


\section{Introduction}

In light of the "great trade collapse" following the financial crisis 2008/2009, there has been increased interest in the role of finance for export business and there is now ample evidence that exports are more vulnerable to financing conditions than domestic sales. ${ }^{1}$ Most countries have state credit guarantee programs to improve access to finance for exporting firms. Recent literature analyzes the effectiveness of such schemes as a means of stimulating exports, value added, and employment. Felbermayr et al. (2012) estimate that state export credit guarantees in Germany, the so-called "Hermes guarantees," increase firms' sales growth by about 4.5 percentage points in the year of the grant, supporting previous evidence of a positive relationship at the aggregate level. ${ }^{2}$ However, evidence on the underlying mechanism is scarce. This is surprising, given that policy makers often refer to financial market frictions to justify the need for state credit guarantees. Moreover, the welfare implications of the state intervention depend crucially on the channels through which state guarantees manifest their effects.

In this paper, we aim to understand why state export credit guarantees in Germany, the so-called "Hermes guarantees" work. After giving an overview of the policy instrument we present a theoretical model to elaborate relevant trade-finance channels. Our following empirical analysis is based on a unique firm-level data set combining transaction-level information on state credit guarantees extended to German firms with the Ifo Business Survey that provides information on firms' export performance. We exploit the detailed information on guarantees and firms to analyze the heterogeneity of the effect of Hermes guarantees on firms' exports in order to understand what characteristics of an export transaction make its success particularly dependent on the state credit guarantee scheme.

Export transactions covered by state credit guarantees are characterized by large volumes and long durations. Besides the risk inherent to the project, they involve the risk of political or economic turmoil in the destination country. A large share of these transactions are destined for developing countries with less developed financial markets, such that finance on a cash-in-advance basis from the importer's side is also relatively more difficult. Thus, these types of projects expose exporters' lenders and investors to substantial amounts of risk and make their financing terms strongly dependent on the financial market's efficiency with regard to risk diversification and the cost of bearing systemic risk.

Drawing on a large literature, we consider financial market agents to be constantly exposed to the risk of illiquidity that is due to the maturity mismatch of their assets

\footnotetext{
${ }^{1}$ For studies at the firm-level see e.g. Greenaway et al. (2007) (United Kingdom), Muûls (2008) (Belgium), Manova et al. (2015) (China), Amiti and Weinstein (2011) (Japan) and Minetti and Zhu (2011) (Italy). Chor and Manova (2012) provide sector-level evidence for US imports during the financial crisis.

${ }^{2}$ Felbermayr and Yalcin (2013) find a positive relationship between sectoral exports and Hermes guarantees that is particularly strong for sectors that depend more on external finance. Moser et al. (2008) also find a positive effect in a country-level study. For Austria, Egger and Url (2006) and Badinger and Url (2013) report positive effects, as do Janda et al. (2013) for the Czech Republic. Auboin and Engemann (2014) find a strong positive effect of export credit insurance on bilateral trade, based on an extensive dataset covering more than 70 countries and public as well as private insurers.
} 
and liabilities (Diamond and Dybvig 1983) or market-based valuation of assets (Allen and Gale 1998) and makes them prone to runs. Bank runs entail costly early liquidation of long-term assets and, potentially, insolvency. Regulatory standards are enacted to reduce the probability of those events by forcing financial institutions to engage in (costly) measures of risk diversification and liquidity management. ${ }^{3}$ This can be accomplished by various means, including portfolio management, hedging, holding cash, issuing subordinate debt or equity, or buying deposit insurance. ${ }^{4}$ These costs of holding risk might be considered as a measure of financial market effectiveness in diversifiying and bearing risk. In an Arrow-Debreu world with complete contingent markets and costless transactions, they would be zero. If, at the other extreme, the risk was not at all diversifiable, financial institutions obliged to maintain a solvency probability of almost one would need to hold the full amount at risk in liquid assets, with costs then reflecting foregone interest.

Competitive financial agents pass on transaction costs to firms by way of charging interest or insurance premia for risky loans that are higher than the actuarially fair compensation for the risk involved and consequently, some projects with positive expected values cannot be profitably financed. State credit guarantees can attenuate this problem, but only to the extent that the state is more efficient at dealing with risk than private financial markets.

Of course, the government could achieve a similar effect on firms' financing cost by subsidizing risk premia. However, in the case of Germany's Hermes guarantees, observable profits and losses associated with the guarantee scheme indicate that, on average, revenues earned from risk premia and fees overcompensate expenses from payment of claims and administration costs. ${ }^{5}$ The realized cumulative profits for the period 1950 to 2013 amount to 3.6 billion Euro, suggesting that the premia adhere to a profitability constraint. ${ }^{6}$

We analyze potential sources of market imperfection and properties of the government that might explain why state credit guarantees for some types of risky projects can be offered at premia lower or equal to market prices without violating the profitability constraint. First, if there are costs to diversifying risk for private agents, the government's "deep pocket" will give it a cost advantage in financing or insuring projects with large values at risk. ${ }^{7}$ The "deep pocket" also frees the government of the need to engage in costly liquidity management, whereas private financial agents are exposed to variable refinancing conditions. Second, if coordination of creditors

\footnotetext{
${ }^{3}$ Current regulation requires financial institutions to hold regulatory capital in an amount such as to achieve a constant solvency probability. Gordy and Howells (2006) show that for the Internal Ratings Based Approach of Basel II, the targeted one-year solvency probability was 99.9 percent.

${ }^{4}$ See Kashyap et al. (2002) for a quantitative assessment of the costs associated with such buffer stocks for U.S. banks.

${ }^{5}$ German state export credit guarantees are administered by a private consortium made up of Euler Hermes Deutschland AG and PriceWaterhousecoopers $A G$, acting on behalf of the federal government. For a detailed description of the guarantee program see Moser et al. (2008)

${ }^{6}$ Numbers stem from the Annual Report 2013 of Euler Hermes. The report is available at http://www. agaportal.de/en/aga/downloads/jahresberichte.html.

${ }^{7}$ As is often argued, its "deep pocket" provides a rationale for the government playing an active role as loan guarantor or deposit insurer; see e.g. Merton (1977), Diamond and Dybvig (1983).
} 
in case of payment default comes at a cost, then the government as a single actor will also have a cost advantage when it comes to asserting claims in debt renegotiations and insolvency proceedings. ${ }^{8}$ And last, we suppose that the government has greater bargaining power in debt renegotiations with entities in foreign countries, which, as we discuss below, often involve other foreign governments. Under any of these conditions, the government can offer guarantees for specific types of projects at lower premia than private capital markets without incurring losses in the long run.

Purchasing state credit guarantees then provides exporters with the opportunity to lower the cost of external finance and thus enhance their competitiveness and increase the profitability of export projects. In our empirical analysis we test this link between participation in the state credit guarantee program and export performance and we confirm the finding in the extant literature that participation in a state export credit guarantee scheme has a positive effect on exports. The focus of our analysis, however, lies in the heterogeneity of the effect of participation with regard to certain characteristics of covered transactions. In particular, we test whether transactions for which we expect the financial market frictions discussed above to be especially detrimental benefit more from the presence of a state credit guarantee scheme.

Our empirical analysis draws on an exceptional dataset which is a combination of all project-specific guarantees issued by Euler Hermes between 2000 and 2010 with monthly survey data on German manufacturing firms from the Ifo Institute's Business Survey. The dataset brings together information on contract size, duration, and riskiness of the publicly insured transactions with firms' individual assessments of their export situation and their demand and financing conditions, as well as employment and balance sheet information. Given the ordinal nature of our variable of interest firms' qualitative assessment of the stock of foreign orders - we use a binary choice model to estimate the effect of Hermes guarantees and analyze how it varies with characteristics specific to the contract, the importer, the exporter, or the time of the grant.

To preview our results, we find that there is systematic heterogeneity of the effect in line with the hypothesized financial market frictions and cost advantages of the state: Hermes guarantees particularly benefit firms that are dependent on external finance, and the effect is stronger for projects with large values at risk or during periods when financing conditions on the private capital market are tight. Moreover, Hermes guarantees have stronger positive effects in cases where the importer also has a guarantor in the background. Our results thus lend support to the hypothesis that the state credit guarantee scheme mitigates frictions on private capital markets by exploiting the government's cost advantages regarding risk diversification and liquidity management, and its greater effectiveness in recovering claims in case of default.

In the following section we describe the German export credit guarantee scheme and discuss in more detail the potential types of financial market frictions relevant to this case. We than formalize the presented arguments in a model and derive testable

\footnotetext{
${ }^{8}$ Transaction costs of this sort have been proposed as one reason for the existence of banks; see Mayer (1988), Sharpe (1990).
} 
predictions. In Section 4 we describe our data sources, explain our empirical strategy, and present the results. Section 5 concludes.

\section{The German State Export Credit Guarantee Scheme}

\subsection{Description of the guarantee program}

The German state credit guarantee program aims at supporting exports of German firms to risky markets. The state justifies its intervention by the failure of financial markets to provide appropriate finance for particular types of export projects. Eligibility of countries and sectors, as well as the costs of coverage are determined in a "gentlemen's agreement" amongst OECD member countries, also known as the OECD Arrangement or the OECD consensus. ${ }^{9}$ In compliance with the agreement, only export transactions involving risk classified as "non-marketable" are eligible for state credit guarantees. Current rules hold that export credit claims against customers located in the European Union or other OECD countries (except Chile, Israel, Mexico, South Korea, and Turkey) with contract durations of less than 24 months are assumed to be marketable and therefore cannot be insured by state institutions. Contracts of longer duration can principally be covered for all countries, but they are still subject to an array of conditions.

The amount of risk by country and in total that is taken on by the Federal Republic of Germany is limited by the so-called "statutory maximum exposure limit," which is decided on every year by an interministerial commitee. Once the limit is reached, additional coverage applications cannot be met. Moreover, projects have to meet local content rules and certain environmental standards in order to qualify for coverage and in general, the interministerial committee reserves the right to reject any project which may have adverse ecological, social, or environmental consequences or which is deemed too risky.

Firms apply on the basis of a well-defined export project for which they seek cover. Table 1 sets out aggregate statistics on applications for cover and guaranteed volumes. Over time, we observe a strong correlation between the volume of applications and the volume of total trade; see Fig. 1. Interestingly, we also observe that this correlation was broken during the economic and financial crisis 2008/2009, where the volume of applications rose sharply while the volume of exports collapsed. Supposedly, during the crisis period firms turned to insurance policies as they faced tighter credit constraints due to banks' limited willingness to take on risk associated with lending to the private sector.

\footnotetext{
${ }^{9}$ Under WTO rules, "the provision by governments (or special institutions controlled by governments) of export credit guarantee or insurance programmes" qualifies as export subsidy and is, thus, outlawed. However, the WTO Agreement on Subsidies and Countervailing Measures exempts those schemes if at least twelve GATT members take part in an "international undertaking on official export credits" that regulates the use of those guarantees.
} 


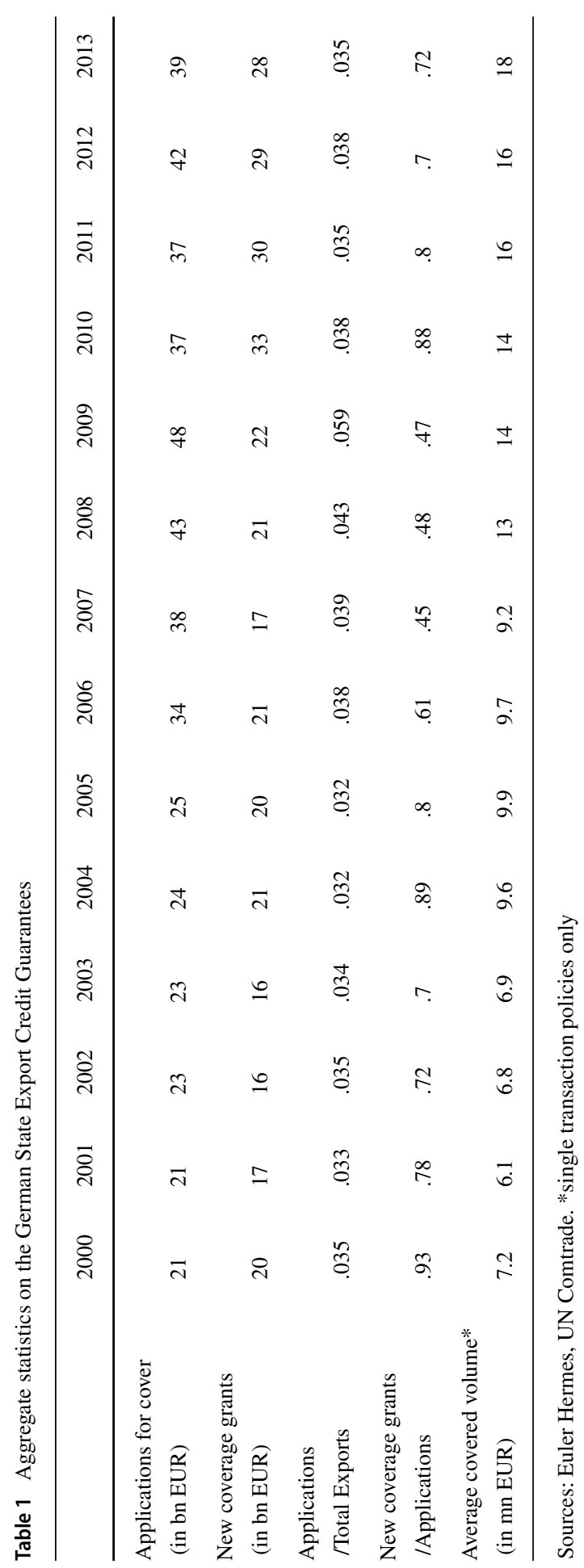




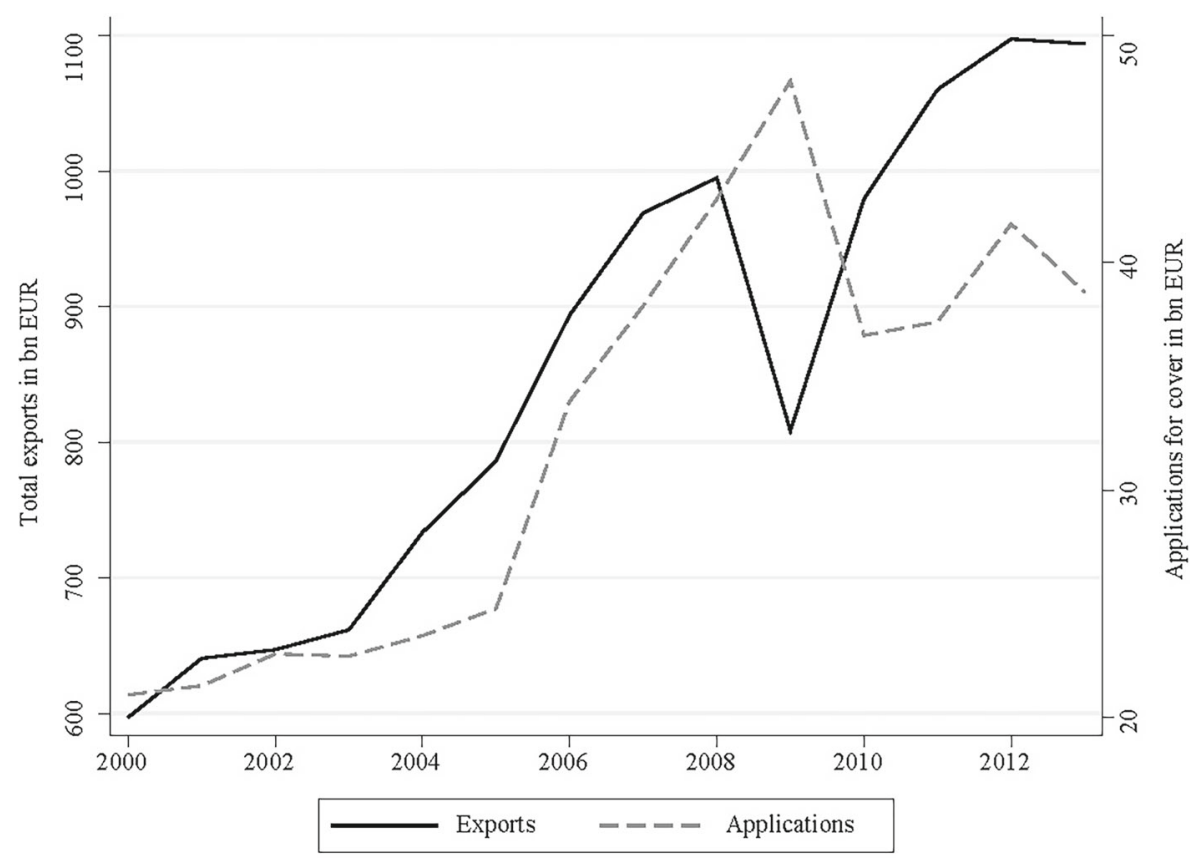

Fig. 1 Total German Exports and Applications for Cover Sources: UN Comtrade, Annual report of Euler Hermes 2013

The increase in demand for guarantees was not accommodated by an increase in supply. The statutory maximum exposure limit was held constant at 117 billion Euro around this time. However, the list of countries eligible for short-term cover was temporarily extended. Nevertheless, the ratio of newly granted coverage to applications reached a low of less than 50\% between 2007 and 2009, supporting the notion that the surge in applications for state credit guarantees was driven by the tighening of conditions on private financial markets rather than by an increase in supply of coverage. The volume of newly granted guarantees increased significantly in 2010 and has remained at this high level since, commensurating with an increase in the statutory maximum exposure limit that reached 145 billion Euro in 2013. ${ }^{10}$

The average size of individual covered transaction has also been increasing over time, reaching 18 million Euro in 2013. ${ }^{11}$ The average volume refers to single transaction policies only, on which we focus in the empirical part. Guarantees of this type cover specific transactions, that is, the type of good, the importer, the value, and the

\footnotetext{
${ }^{10}$ All numbers in this section are from the Euler Hermes Annual Report 2013, unless stated otherwise.

${ }^{11}$ This figure is based on the transaction-level data set provided to us by Euler Hermes.
} 
duration are specified. ${ }^{12}$ Compared to the average size of loans extended by German banks, transactions covered by Euler Hermes are very large. ${ }^{13}$

Guarantee premia follow a price schedule which takes into account country risk (based on the OECD country risk classification), duration of the credit risk, and the riskiness of the project which is assessed and rated by Euler Hermes. In some cases importers use guarantees from their respective governments or central banks, or from private institutions to enhance their creditworthiness. Euler Hermes also collects application fees to cover administrative cost.

Guarantees cover losses due to commercial risk as well as political risk. The former comprises incidences of payment delay or default caused by insolvency of the importer. Political risk comprises, among others, non-payment incidences caused by political turmoil, legislative or administrative measures in the destination country, or losses due to restrictions in the international payment system that lead to nonconvertibility or non-transferability of payments. In case that a guarantee is drawn due to any of the above reasons, exporters or their banks receive the guaranteed amount (at most $95 \%$ of the total volume of the export transaction) from the state. In turn, the state takes over the claim against the importer or, respectively, against the importer's guarantor, and engages in debt restructuring or debt renegotiations. Many outstanding claims, particularly those resulting from events classified under political risk, are handled by the Paris Club as part of multilateral negotiations on debt restructuring. ${ }^{14}$ In 2013, the German federal government held claims of 4.2 billion Euro, of which 1.2 billion were regulated under official rescheduling agreements.

The profit and loss account of the state credit guarantee program thus comprises premia, fees, and recoveries of outstanding claims on the income side, and claims payments as well as administrative cost on the expenditure side. In the official figures on the profit and loss account interest payments are excluded on the income side, because the government's refinancing cost in years of losses were also not taken into account. ${ }^{15}$ Figure 2 shows annual and cumulative profits of the agency since 1950. In the early years the program was run at much smaller scale than today, five-year periodical gains and losses did not exceed a level of 100 million Euro. In the late eighties/early nineties substantial losses associated with the collapse of the Soviet

\footnotetext{
${ }^{12}$ Single transaction policies make up the largest part of the total volume of covered exports. Other types are wholeturnover policies, which are provided for a specific product and one (or sometimes more than one) destination market in a given period of time without specifying the importer, and revolving policies, which can be used for repeated similar transactions. The latter are quantitatively only of marginal importance.

${ }^{13}$ It is hard to come by exact statistics on average loan size extended by German banks. Schertler et al. (2006) report that the average lending relationship between an individual bank (or a group of banks) and an individual firm in Germany amounts to 5 million EUR. This figure is based on data from the German credit register and constitutes an upper bound for the size of individual loans, since the lending relationship can comprise multiple loans between the same bank-firm pair and also because the credit register contains only bank-firm relationships which crossed the reporting threshold of 1.5 million EUR at least once during a given quarter.

${ }^{14}$ The Paris Club is a non-institutionalized association of creditor countries that was formed to facilitate multilateral debt renegotiation, restructuring, and cancellation agreements with indebted countries.

${ }^{15} \mathrm{~A}$ back-of-the-envelope calculation shows that for all levels of the government's annual refinancing cost below $12.75 \%$ cumulative returns would still be positive.
} 


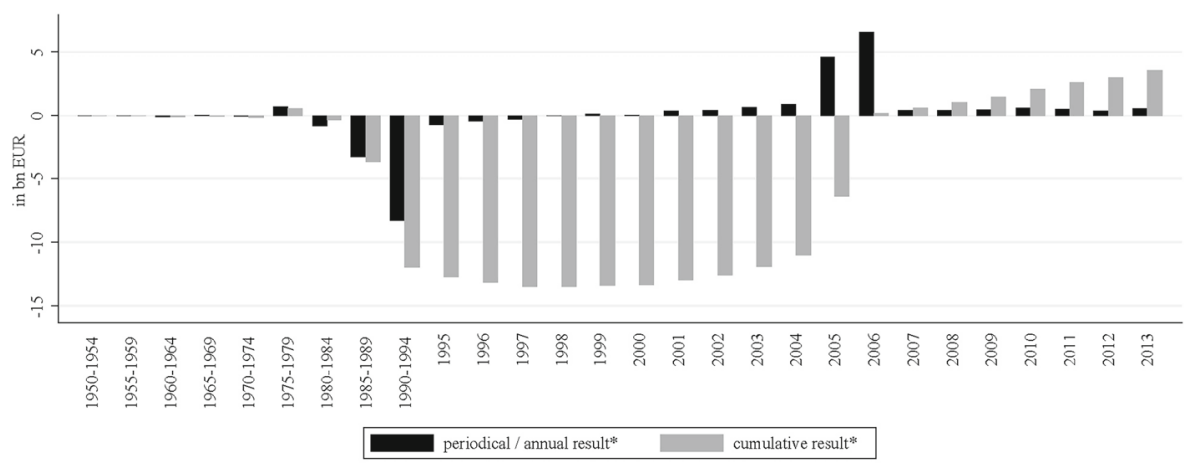

Fig. 2 Net Gains and Losses of the German State Export Credit Guarantee Program. Source: Annual report of Euler Hermes 2013. *excluding interest

Union were incurred, rendering the cumulative result strongly negative. In 1999, the annual result turned positive and has remained so to date. ${ }^{16}$ In 2005 and 2006, Russia paid back about 13.6 billion Euro, ${ }^{17}$ resulting in large positive annual gains and rendering the cumulative result positive. Negotiations with Russia were also conducted by the Paris Club. The cumulative result has been positive since then, reaching 3.6 billion Euro in 2013. This figure strongly suggests that on average premia are set in a way that adequately compensates for the risk taken on by the state. ${ }^{18}$

Figure 3 provides a breakdown of the profit and loss account for the period 2000 to 2013. On the expenditure side, commercial claims make up the bulk of losses in most years, but losses associated with political risk are also substantial. In 2006, for example, about 50 percent of the total amount of claims (292.9 million Euro) were political risk claims. Administration cost are negligible compared to claims payments. Recoveries accounted for the larger share on the income side until 2007. In more recent years, premia and fees have been the major source of income.

\subsection{Financial market frictions and the role of State Export Credit Guarantees}

If we take for granted that the state credit guarantee scheme is operating profitably, the question why private financial agents do not step in to provide similar types of insurance is immediate. In this section, we discuss several market frictions and characteristics of the state that could rationalize a cost advantage of a public guarantee

\footnotetext{
${ }^{16}$ Interestingly, as Dewit (2001) points out, in 1995 the WTO Agreement on Subsidies and Countervailing Measures came into force, which significantly strengthened the rules for provision of state export credit guarantees. In particular premia policies yielding long-term losses were outlawed and countries supposedly suffering from those policies were granted access to the Dispute Settlement System.

${ }^{17}$ See the annual report of Euler Hermes 2006.

${ }^{18}$ It is noteworthy here that the Paris Club regularly agrees to reschedule debt in favor of developing countries. In 2010, for example, Germany agreed to a total debt forgiveness of 643 million Euro under the HIPC (Heavily Indebted Poor Countries)- Initiative of the Paris Club. This strengthens the case for the program itself being operated at non-negative returns.
} 


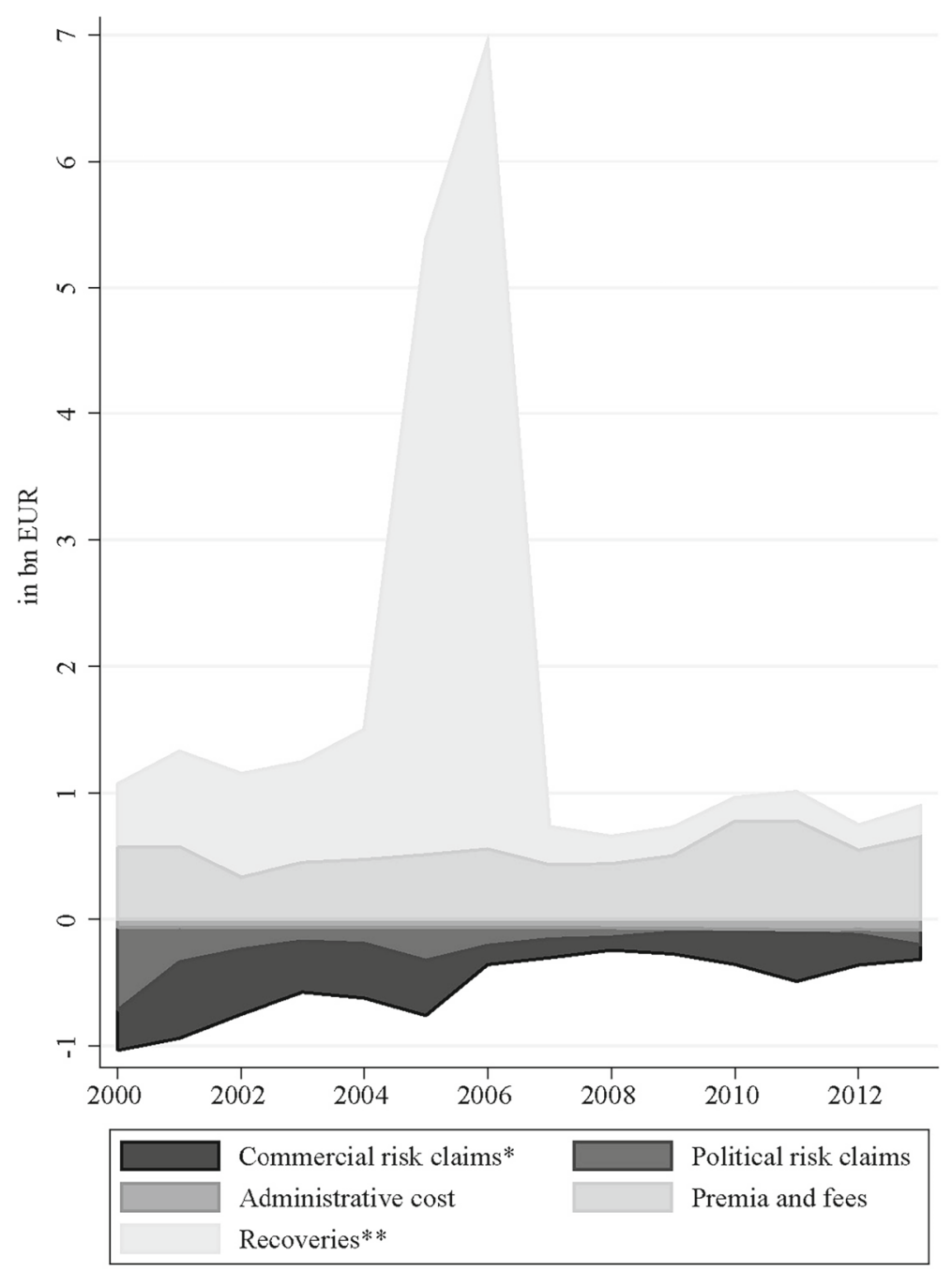

Fig. 3 Profit and Loss Account of the German State Credit Guarantee Program. Source: Annual reports of Euler Hermes. *including exchange rate risk. ** excluding interest

scheme for particular types of transactions against the backdrop of a financial market faced with liquidity risk and regulation aimed at enforcing measures that ensure solvency.

Several distinctive characteristics of transactions covered by Euler Hermes may play a role here. First, as described in the previous section, the transactions covered by German state credit guarantees are very large. Hence, they bear relatively large amounts of idiosyncratic risk. The positive cumulative result of the scheme masks substantial variation in annual results. As shown in Fig. 2, between 1982 and 1998 repeated annual losses were incurred, involving amounts up to 2.5 billion Euro. With 
its largely unrestricted refinancing capacity the state can withstand repeated periodic losses associated with large risky projects, for which the positive expected value materializes only in the very long run. Of course, a perfectly functioning capital market should be able to diversify these types of risk as well. However, if risk diversification is costly, the government's "deep pocket" endows it with a comparative advantage in financing projects that involve large values at risk.

Moreover, export transactions to risky countries involve political risk on top of idiosyncratic project-specific risk. As discussed in the descriptive sections, losses associated with political risk make up a significant share of the programs expenses. Political risk includes a substantial amount of systemic risk, which implies that private financial agents need to engage in asset management to meet the solvency probability targeted by regulators. Long duration of credit contracts increase the need for liquidity management and tighter refinancing conditions increase the associated cost. In contrast, the government's deep pocket frees it of the need to engage in liquidity management and hence endows it with a cost advantage in bearing systemic risk. ${ }^{19}$

Finally, the profit and loss account of the state credit guarantee program reveals that a substantial amount of outstanding claims can be recovered each year. Potentially, the government's bargaining power and its access to the Paris Club constitute a cost advantage when it comes to recovering claims through debt renegotiation or restructuring as part of insolvency proceedings, in particular in cases where the debtors are foreign governments. Moreover, as a single actor the government does not face coordination cost in contrast to a dispersed set of private agents who finances a project jointly through the private capital market in order to share the risk.

We formalize these possible comparative advantages of the state in the following theoretical framework and derive testable hypothesis for the succeeding empirical analysis.

\section{The model}

In this section we develop a partial equilibrium model of international trade with heterogeneous firms that are confronted with uncertainty about the success of export transactions. Our model builds on Manova (2013), who analyzes heterogeneity in firms' need for and access to external finance in a framework based on Melitz (2003). We introduce importer default risk into the model, allow the refinancing conditions of the banking sector to vary, and derive conditions under which the use of credit guarantees affects the extensive and intensive margin of firms' exports.

\footnotetext{
${ }^{19}$ Of course, the refinancing capacity of the German government is not unlimited in practice. However, it seems reasonable to assume that it exceeds the capacity of private agents on financial markets significantly. Moreover, the total amount of risk covered with Hermes guarantees at a given point in time is small compared to Germany's GDP. In 2010, the ceiling on total risk assumed was 120 billion Euro (less than $5 \%$ of GDP).
} 


\subsection{Demand}

Demand for variety $a$ of a differentiated good that is imported by firm $j$ is derived from a symmetric CES utility function over a set of differentiated varieties and results as

$$
q_{j}[a]=p_{j}[a]^{-\varepsilon} A_{j},
$$

where $p_{j}[a]$ is the price of variety $a$ that importer $j$ faces and $A_{j}$ is a demand shifter. $\varepsilon>1$ is the elasticity of substitution between any two varieties. Due to fixed costs of production, any variety is produced by only one firm, hence $a$ subsumes the exporter index. In the following, we always consider a specific transaction between a pair $(a, j)$, for ease of notation we drop the importer index $j$.

\subsection{Firm behavior}

Differentiated varieties in each country are produced by an exogenously given number of firms. To produce, ship, and sell $q$ to a foreign country, firms have to pay fixed costs $f$ and variable costs $a$ per unit of $q \cdot{ }^{20}$ We assume that firms differ with respect to productivity, that is, they face different unit costs of production $a$, where $a \in\left[a_{L}, a_{H}\right]$ and $a_{H}>a_{L}>0 .{ }^{21}$ Fixed and variable costs must be paid upfront before payment from the importer is received. We assume that firms have an amount $k$ of liquid funds available to cover these upfront costs. Furthermore, they can borrow from a competitive banking sector. Payment for exported goods is uncertain due to the possibility of importer default, which occurs with probability $1-\lambda$. We assume that the firm has no other sources of revenue; hence, if the importer defaults, the firm is forced to default on its debt. ${ }^{22}$ The importer's default risk will thus be reflected in the costs of external finance. Firms can lower the interest rate on the loan by contracting a credit guarantee. Before we discuss the financial sector in detail, we first derive firms' optimal export behavior for exogenously given costs of external finance.

In this monopolistic competition framework, firms set prices, choose how much to borrow, and how much to cover with a guarantee. Whenever the costs of external finance exceed the firm's opportunity costs of its own liquid funds, the firm will use external finance only after its internally available funds have been exhausted. Furthermore, if the firm's liquid funds are small relative to the size of the project, in particular if it has to rely on external finance no matter how much it is going to sell because its liquid funds $k$ are smaller than the fixed set-up costs $f$, then the choice of the optimal price is independent of $k$. To keep the model as simple as possible, we proceed under the assumptions that external finance is more costly than internal

\footnotetext{
${ }^{20}$ Costs are expressed in terms of the price of a fixed input bundle. We scale units such that this price is normalized to 1 . Without loss of generality we set variable trade costs to zero.

${ }^{21}$ We use $a$ to denote both the variety and the productivity level of the firm. Assuming that $a$ corresponds to a draw from a continuous distribution over the interval $\left[a_{L}, a_{H}\right]$, no two firms can have the same productivity level.

${ }^{22}$ We make this assumption for the sake of simplicity. The qualitative results of our model do not change as long as the exporter's default risk is positively associated with the importer's default risk.
} 
finance and that the amount of liquid funds is small, so that $k<f$. Appendix $\mathrm{C}$ shows that our results are qualitatively the same in the general case.

Let $R^{o}$ denote the costs of external finance for a given project, with $o \in[B, G]$ indicating whether the firm finances the export project only through a bank $(B)$ or with the help of a credit guarantee $(G)$ to eliminate default risk. Furthermore, let $\bar{R}$ denote the gross return to the firm's alternative investment. For a given financing mode $o$, the firm then only chooses its price to maximize expected profits given by

$$
\max _{p} \lambda p q-\bar{R} k-\lambda R^{o}(a q+f-k) \quad o \in[B, G],
$$

subject to demand as in Eq. 1. Expected profits consist of the uncertain payment $\lambda p q$, minus the firm's opportunity costs of investing its liquid funds $k$ and the costs of borrowing the remaining part of the investment $a q+f-k$ at $R^{o}$. The latter are, however, incurred only if the project is successful. Optimal prices and quantities result as

$$
\begin{aligned}
& p^{*}[a]=\frac{R^{o} a}{\theta} \text { with } \frac{1}{\theta}=\frac{\varepsilon}{\varepsilon-1}, \\
& q^{*}[a]=\left(\frac{R^{o} a}{\theta}\right)^{-\varepsilon} A .
\end{aligned}
$$

Let

$$
r[a]=p[a]^{*} q[a]^{*}=\left(\frac{R^{o} a}{\theta}\right)^{1-\varepsilon} A
$$

denote the optimum revenue of the firm. Maximum expected profits are then given by

$$
\pi^{*}[a]=\frac{\lambda}{\varepsilon} r[a]-\bar{R} k-\lambda R^{o}(f-k) .
$$

The first term on the right-hand side of Eq. 6 denotes operating profits, which are proportional to the firm's revenue, as in Melitz (2003). The remaining terms summarize the effective set-up costs on which the firm spends all its liquid funds $k$, and the amount $f-k$ that is borrowed at the gross interest rate $R^{o}$ and repaid only with probability $\lambda$. Higher costs of external finance $R^{o}$ lead to lower expected profits by increasing both the marginal costs as well as the fixed set-up costs. Optimal expected revenue increases in productivity $1 / a$; hence, conditional on the demand and financing conditions, a firm needs to be sufficiently productive in order to break even. The break-even productivity level $1 / \bar{a}^{o}$ results implicitly from the zero-profit condition $\pi^{*}[a]=0$, which, in accordance with Eq. 6, follows as

$$
\frac{\lambda}{\varepsilon} r\left[\bar{a}^{o}\right]=\lambda R^{o}(f-k)+\bar{R} k .
$$

Accordingly, both the intensive and the extensive margin of the firm's exports are affected by the costs of external finance. We summarize the relationship between $R^{o}$ and the firm's export decisions in Result 1.

Result 1. An increase in the costs of external finance $R^{o \prime}$ with $o^{\prime} \in[B, G]$ weakly increases the profitability threshold $1 / \bar{a}^{o^{\prime}}$ and weakly decreases the firm's optimal 
level of sales for a given export transaction. The effect on the profitability threshold is stronger for firms with small liquid funds.

Proof The result follows from differentiating and cross-differentiating $r[a]$ and the right-hand-side of Eq. 7 with respect to $R^{o^{\prime}}$ and $1 / \bar{a}^{o^{\prime}}$, for $o^{\prime} \in(B, G)$. Due to the fact that the firm may be operating under the alternative financing mode $o \neq o^{\prime}$ and is thus not affected, Result 1 describes weak inequalities. Details are found in Appendix A.

We next describe the banking sector and the credit guarantee scheme and derive the firm's financing costs $R^{B}$ and $R^{G}$ for the two available financing modes: pure bank finance $(B)$ or bank finance with a credit guarantee $(G)$.

\subsection{The banking sector}

We assume that the banking sector is perfectly competitive and banks can refinance themselves at an exogenous (gross) interest rate $\bar{R} \geq 1 .^{23} \bar{R}$ captures the state of the financial market environment. High refinancing rates may reflect, for example, liquidity shortages or increases in uncertainty as experienced during financial crises. Banks are risk-neutral, but obliged to hedge the risk in their balance sheet to prevent runs. ${ }^{24}$ We take a parsimonious approach to modeling the hedging; we assume banks to bear constant costs $c^{B} \in\left[0, \frac{\bar{R}-1}{\bar{R}}\right]$ per unit of the value at risk in their balance sheet to ensure liquidity at any point in time. We assume that $c^{B}$ reflects the bank's cost-minimizing choice among the possible means of doing so, including portfolio management, hedging, insurance, or holding buffer stocks in the form of equity, securities, or cash. $c^{B}=\frac{\bar{R}-1}{\bar{R}}$ corresponds to the most expensive case where banks must hoard cash. Furthermore, suppose that in the event of borrower default a fraction $b^{B} \in[0,1]$ of the claim can be recovered from the trade partner in the destination country as part of insolvency proceedings. ${ }^{25} \mathrm{We}$ summarize the parameters characterizing the financing environment in the set $\mathcal{B}=\left\{\bar{R}, b^{B}, c^{B}\right\}$. Then, the gross interest rate that a bank facing financing conditions $\mathcal{B}$ and perfect competition can offer on a loan of amount $L$ with default risk $1-\lambda$ is given by the following no-arbitrage condition:

$$
\lambda R^{B} L+(1-\lambda) b^{B} R^{B} L=\bar{R} L+\bar{R} c^{B}(1-\lambda)\left(1-b^{B}\right) R^{B} L,
$$

subject to a financing profitability constraint

$$
\lambda+(1-\lambda) b^{B}>\bar{R} c^{B}(1-\lambda)\left(1-b^{B}\right) .
$$

\footnotetext{
${ }^{23}$ Opportunity costs of money are normalized to unity in the second period in which profits are realized and loans are repaid (or not).

${ }^{24}$ Assuming that all banks comply with this obligation, a bank run, which we could think of as a case of prohibitively high refinancing costs, is ruled out. This justifies our normalization assumption (see previous footnote).

${ }^{25}$ We can consider $b^{B}$ as the outcome of the bank's cost-minimization problem with respect to the effort expended on recovering claims or corporate rescues, thus capturing both the costs of coordination of creditors and the bargaining power in debt renegotiations.
} 
The no-arbitrage condition (8) requires that the expected return - consisting of the borrower's payment $R^{B} L$ that arrives with probability $\lambda$ and the amount $b^{B} R^{B} L$ that is recovered in case of default - equal the refinancing costs of the bank $\bar{R} L$ plus the costs of hedging the value at risk $\bar{R} c^{B}(1-\lambda)\left(1-b^{B}\right) R^{B} L$. Note that if the costs of hedging the risk are sufficiently high, the expected return to financing the project becomes negative and the financing profitability constraint is violated. This is more likely the smaller $\lambda$ or $b^{B}$ or the higher $\bar{R}$. We set $R^{B}=\infty$ in this case, assuming that banks do not offer finance for projects with negative expected values. If the financing profitability constraint is met we can solve (8) for $R^{B}$, which yields

$$
R^{B}:=R^{B}[\lambda, \mathcal{B}]=\frac{\bar{R}}{\rho^{B}} \quad \text { with } \quad \rho^{B}=\lambda+(1-\lambda) b^{B}-\bar{R} c^{B}(1-\lambda)\left(1-b^{B}\right) .
$$

Hence, the interest rate is determined by the bank's refinancing costs and a projectspecific risk adjustment factor $\rho^{B}$. In a world without payment uncertainty (either $\lambda$ or $b^{B}$ equal one), banks would simply pass through their refinancing costs $\bar{R}$ to firms. Suppose for expositional purposes but without loss of generality that $b^{B}=0$. Then, in an Arrow-Debreu world with costless risk diversification $\left(c^{B}=0\right)$, firms would face an interest rate $\frac{\bar{R}}{\lambda}$ reflecting banks' refinancing costs augmented by an actuarially fair risk premium. If in this case $\bar{R}$ reflects the true opportunity costs of finance in the economy, then it can be seen from the firms' profit-maximization problem that private marginal costs are perfectly aligned with social marginal costs. ${ }^{26}$

In general, it holds that in a competitive financial market transaction costs are passed on to the borrowing firms. To what extent these costs matter depends on characteristics of the project and the banks' refinancing conditions. We summarize the relationship between financial market conditions and the project-specific interest rate in Result 2.

Result 2. The project-specific costs of external finance with pure bank financing, $R^{B}$, are high if refinancing costs $\bar{R}$, the costs of risk diversification $c^{B}$, or the probability of default $1-\lambda$ are high, or if the recovery rate $b^{B}$ is low. The effect of higher costs of diversification or a lower recovery rate is stronger if refinancing costs or the probability of default are high.

Proof See Appendix A.

\subsection{The Credit Guarantee Scheme}

Suppose that firms can insure themselves against default risk by means of a guarantee or an insurance that pays out in the event of importer default. The main difference

\footnotetext{
${ }^{26}$ Note that in contrast to the work by Matsuyama (2008), Manova (2013), and Feenstra et al. (2014), moral hazard is absent from our model. Furthermore, even when there are frictions on financial markets in terms of $c>0$, the incentives of the bank and the firm are well aligned, and the bank's participation constraint, that is key in the aforementioned models (sometimes referred to as "cash-flow constraint" or "financing constraint"), is never more restrictive than the firm's participation constraint (break-even condition) Eq. 7. This result holds for the case where external finance is more costly than internal finance. In the general case that we treat in the Appendix, the borrowing constraint becomes relevant again.
} 
between these two instruments is that the guarantor takes over the claim against the contract partner in case of default, which the insurer does not. From the firm's point of view, both schemes are ceteris paribus identical in their effect since we have (implicitly) set its own recovery rate equal to zero. ${ }^{27}$ Thus, we can describe an insurance as a special case of a guarantee, namely, the single case where the recovery rate of the guarantor $b^{G}$ is zero. ${ }^{28}$

We assume that the guarantor (potentially the government, but not necessarily so) offers the following financing terms: It guarantees to pay the amount $G \leq p q$ in the event of default, in exchange for a premium payment of $\gamma G$. In the event of default, the guarantor assumes the part $G$ of the claim against the importer and is able to recover a share $b^{G} \in[0,1]$. Furthermore, just like for banks, the guarantor has to hedge risk in its balance sheet, for which it incurs $c^{G} \in\left[0, \frac{\bar{R}-1}{\bar{R}}\right]$ per unit of value at risk. We summarize the guarantor's financing conditions in $\mathcal{G}=\left\{\bar{R}, b^{G}, c^{G}\right\}$. Except for $\bar{R}$, we allow them the potential to be different from the bank's parameters $\mathcal{B}$, reflecting differences in the guarantor's ability to diversify risk or recover claims. In a competitive insurance market, the premium $\gamma$ is then determined by the following no-arbitrage condition

$$
\gamma G \bar{R}+(1-\lambda) b^{G} G=(1-\lambda) G+c^{G} \bar{R}(1-\lambda)\left(1-b^{G}\right) G,
$$

subject to a profitability constraint

$$
\lambda+(1-\lambda) b^{G}>\bar{R} c^{G}(1-\lambda)\left(1-b^{G}\right) .
$$

The no-arbitrage condition of the guarantor states that the return from the premium $\gamma G$, that can be invested immediately at rate $\bar{R}$, and the return from acquiring the claim in the event of default $(1-\lambda) b^{G} G$ equal the expected payment $(1-\lambda) G$ plus the costs of hedging the value at risk in the balance sheet. Similar to the case of the bank, the guarantor is faced with a profitability constraint that requires the expected return to exceed the costs, which is more likely if $c^{G}$ is small, $\lambda$ or $b^{G}$ are high, or $\bar{R}$ is small. If the constraint fails to holds, we set $\gamma=\infty$. Otherwise, we can solve (10) for $\gamma$ to obtain

$$
\gamma:=\gamma[\lambda, \mathcal{G}]=\frac{(1-\lambda)-(1-\lambda) b^{G}+c \bar{R}(1-\lambda)\left(1-b^{G}\right)}{\bar{R}} .
$$

With the guarantee in hand, firms can obtain credit from the bank at the "risk-free" rate $\bar{R}$.

To show how the firm's costs of external finance under bank financing with a credit guarantee are determined, we consider again the firm's profit-maximization problem.

\footnotetext{
${ }^{27}$ Note that we can do this without loss of generality as long as the recovery rate of the firm is smaller than that of the bank or guarantor, as we can think of $\lambda$ as reflecting two factors: the repayment probability and the firm's recovery rate.

${ }^{28}$ Another difference between the two instruments is that the guarantee cannot cover more than the value of the contract, whereas, potentially, the insured amount can exceed the loss associated with the actual default. This would become relevant if the insurer was able to offer a premium that is actuarially fair or favorable from the point of view of the firm, even though the recovery rate of the insurer is zero. We neglect this possibility, since, as will become clear below, arbitrarily small transaction costs are sufficient to render the insurance premium non-favorable when $b=0$.
} 
Clearly, for the risk-neutral firm any coverage is profitable only if it decreases the costs of external finance; hence, a guarantee will not be purchased if $R^{G}>R^{B}$. It is straightforward to show that firms will want to cover exactly the share of the transaction that they finance externally when $R^{G}<R^{B}$; see Appendix C. Under the assumption that external finance is more costly than internal finance, the share of the investment that is financed externally is given by $\ell=a q+f-k$. However, if the firm decides to purchase a guarantee, it needs additional funds in the first period. The total amount borrowed from the bank is thus $L=\ell+\gamma G$. Furthermore, to fully eliminate the default risk for the bank, the guarantee must cover not only the loan but also the associated interest payment. That is, if the firm chooses to fully cover the loan $L$, it needs to purchase a guarantee in the amount $G=\bar{R} L . G$ is thus given by $G=\frac{\bar{R}}{\bar{R}-1}(a q+f-k)$. With such a guarantee, the bank's credit risk is eliminated and hence the competitive interest rate for the covered loan is equal to $\bar{R}$. The firm's expected profit-maximization problem is then

$$
\begin{aligned}
& \max _{p} \lambda p q+(1-\lambda) G-\bar{R} k-G \\
= & \lambda p q+(1-\lambda) \frac{\bar{R}}{1-\bar{R} \gamma}(a q+f-k)-\bar{R} k-\frac{\bar{R}}{1-\bar{R} \gamma}(a q+f-k) .
\end{aligned}
$$

With probability $\lambda$ the firm receives the value of its sales from the importer, with probability $1-\lambda$ the guarantee pays off in the amount $G$. With certainty, all liquid funds $k$, which have opportunity costs of $\bar{R}$, are invested and the loan plus interest $G=\bar{R} L$ is repaid. Rearranging (12) shows that expected profits are given by Eq. 6 with

$$
R^{G}=\frac{\bar{R}}{\rho^{G}} \quad \text { and } \quad \rho^{G}=1-\bar{R} \gamma=\lambda+(1-\lambda) b^{G}-c \bar{R}(1-\lambda)\left(1-b^{G}\right) \text {. }
$$

In analogy to Result 2 we can establish how financial market conditions affect the financing cost of firms using credit guarantees. This is summarized in Result 3.

Result 3. The project-specific costs of external finance under the financing scheme with a credit guarantee $R^{G}$ are high if refinancing costs $\bar{R}$, the costs of risk diversification $c^{G}$, or the probability of default $1-\lambda$ are high, or if the recovery rate $b^{G}$ is low. The effect of higher costs of diversification or a lower recovery rate is stronger if refinancing costs or the probability of default are high.

\section{Proof See Appendix A.}

Comparing the costs of external finance under both financing schemes ((9) and (13), observing (11)) shows that they are similar if risk diversification costs and the recovery rates of the bank and the guarantor do not differ for a given export transaction, that is, if $c^{B}=c^{G}$ and $b^{B}=b^{G}$ so that $\rho^{B}=\rho^{G}$. This is a direct implication of the risk-neutrality assumption. From Eq. 2 it is immediate that expected profits with and without a guarantee are equivalent if the financing costs with a guarantee $R^{G}$ equal the costs of pure bank financing $R^{B}$. 


\subsection{Testable hypotheses about the effects of State Export Credit Guarantees}

Suppose firms have chosen the financing mode which minimizes their costs of external finance given financing conditions of competitive banks, $\mathcal{B}$, and competitive guarantors, $\mathcal{G}$. Then, credit guarantees provided by a public agency that makes nonnegative profits, or, in other words, observes a similar no-arbitrage pricing condition as private agents on competitive markets (cp. Equations 8 and 10), will be used only if the government has a cost advantage. Suppose this is true, for example, due to stronger bargaining power or because the government faces lower (no) costs of risk diversification.

By lowering the cost of external finance, state export credit guarantees improve exporters' competitiveness and may thus enable them to realize higher sales on foreign markets. This is the main prediction we are taking to the data. First, we look at the average effect of participation in the Hermes guarantee scheme on exports and interact it with measures of firms' dependence on external finance to test whether state credit guarantees lead to higher exports because they lower the cost of external finance. The same effects, of course, would arise if the government was subsidizing the guarantees. Yet, the empirical fact that the German state credit guarantee scheme has yielded non-negative cumulative profits over a period of more than 60 years strongly suggests that the premia charged by Euler Hermes adhere to a profitability constraint.

Moreover, we test whether state credit guarantees are particularly important for export transactions exhibiting characteristics for which, based on the above discussion, we expect the government's cost advantage in providing insurance to be particularly strong. That is, we analyze whether the volume of covered transactions matters, expecting that cost of risk diversification or coordination make access to finance for these projects through private markets less attractive. Next, we look at the private sectors' refinancing conditions expecting that participation in the state credit guarantee scheme is particularly beneficial when tight refinancing conditions make private financial agents' liquidity management more costly. Finally, we exploit information on the presence and type of a guarantor on the importer's side to test whether state credit guarantees are particularly effective when a guarantor, and in particular a foreign government, is involved on the importer's side, as we expect bargaining power and lower coordination cost in potential debt renegotiations to be relatively more important in these cases.

Testable Hypotheses To summarize, we test the following hypothesis regarding the relationship between firms' participation in the state export credit guarantee scheme and their export performance:

i. Participation leads to higher export,

The effect of participation is stronger

ii for firms that rely more on external finance,

iii in times when refinancing conditions of the private financial market are tight,

iv for transactions characterized by large volumes,

$\mathrm{v}$ and if a guarantor is involved on the importer's side. 


\section{Empirics}

\subsection{Data}

Euler Hermes provided us with a dataset including all covered export transactions between 2000-2010, of which we use all single transaction policies. We are able to identify 684 firms (13\% of all firms that have used a single transaction policy at least once during the sample period) in the Ifo Business Survey. The use of lagged values in our preferred estimation specification somewhat reduces our estimation sample, leaving us with 2,659 covered transactions by 521 firms in a total pool of 3,964 firms that we observe continously over the period from January 2000 to December 2010. For each covered transaction the dates of the first and the last shipment are registered. We consider a firm as "treated" with a guarantee during the period spanned by those two observations. Furthermore, the guarantee data contains Euler Hermes' risk rating of importers which is based on the class of the importer's guarantor (state, bank, private, no guarantor) and a rating on a numerical scale within each class. Since the number of observations in many bins is small, we collapse the risk rating into four categories: 1 "no guarantor/unknown," 2 "private guarantor," 3 "foreign bank," and 4 "foreign state/foreign central bank." When firms have multiple insured transactions at the same time, we pool the covered volumes together, assigning all respective types of guarantors to this one observation.

The Ifo Business Survey covers about 7,000 firms which are surveyed on a monthly basis. In the questionnaire, firms are asked to appraise their own business conditions and the economic environment in general, choosing between three or four possible answers typically coded as 1 "better than usual," 2 "as usual," 3 "worse than usual," and, occasionally, 4 "does not apply." 29 For some variables, such as employment, the survey asks for the actual numbers. ${ }^{30}$ We use firms' assessment of their stock of foreign orders as dependent variable in our estimation. The respective survey question refers to the current stock of settled deals and the variable takes on the four values described above. Since we primarily estimate a binary choice model, we collapse the categories "as usual,"“worse than usual," and "no exports/does not apply" into one. Moreover, we use firms' assessment of expected exports (1 "decrease" 2 "stay the same" 3 "increase") and the general demand situation (1 "worsened" 2 "unchanged" 3 "improved"), as well as the indicator variable Unconstrained, reflecting firms' assessment of production constraints (1 "yes" 2 "no"), as independent variables. Table 8 in the Appendix contains the respective survey questions. ${ }^{31} \mathrm{We}$

\footnotetext{
${ }^{29}$ For ease of interpretation, we recoded the variables so that 3 "higher," 2 "as usual," 1 "lower."

${ }^{30}$ The survey is actually conducted at the product level, although only some questions are product specific. The number of products per firm is small and equals 1 in the majority of cases. Furthermore, survey answers within firms across products are very strongly correlated; hence, we feel safe dropping multiple products randomly.

${ }^{31}$ The original questions and answers are available from the authors upon request.
} 
Table 2 Summary statistics of estimation sample

\begin{tabular}{|c|c|c|c|c|c|c|}
\hline Estimation sample & & Obs & Mean & Std. Dev. & Min & Max \\
\hline Stock of for. orders & binary & 210,371 & 0.10 & 0.30 & 0 & 1 \\
\hline Demand & ordinal & 210,371 & 1.99 & 0.64 & 1 & 3 \\
\hline Employment & & 210,371 & 2,706 & 16,845 & 1 & 200,000 \\
\hline ExpectExp & ordinal & 210,371 & 2.06 & 0.53 & 1 & 3 \\
\hline Unconstrained & binary & 210,371 & 1.61 & 0.29 & 1 & 2 \\
\hline Ibrate & in $\%$ & 210371 & 2.96 & 1.32 & 0.64 & 5.11 \\
\hline WorkingCap & in bn. EUR & 60,695 & 42.2 & 141 & $-1,290$ & 2,550 \\
\hline CashFlow & in bn. EUR & 53,379 & 34.2 & 183 & $-1,080$ & 4,670 \\
\hline Tangibles & in bn. EUR & 65,382 & 49.8 & 246 & 0 & 6,260 \\
\hline ContractSize & in mn. EUR & 2,659 & 3.25 & 16.2 & 0 & 445 \\
\hline \# Firms & & 3,964 & & & & \\
\hline \multicolumn{7}{|c|}{ Estimation sample - Hermes firms } \\
\hline Stock of for. orders & binary & 36,375 & 0.14 & 0.35 & 0 & 1 \\
\hline Demand & ordinal & 36,375 & 2.01 & 0.63 & 1 & 3 \\
\hline Employment & & 36,375 & 2,162 & 10,600 & 3 & 191,200 \\
\hline ExpectExp & ordinal & 36,375 & 2.11 & 0.54 & 1 & 3 \\
\hline Unconstrained & binary & 36,354 & 1.63 & .28 & 1 & 2 \\
\hline Ibrate & in $\%$ & 36,375 & 2.97 & 1.30 & 0.64 & 5.11 \\
\hline WorkingCap & in bn. EUR & 13,133 & 53.8 & 98.7 & -58.6 & 719 \\
\hline CashFlow & in bn. EUR & 12,538 & 24.3 & 109 & $-1,080$ & 1,240 \\
\hline Tangibles & in bn. EUR & 13,384 & 50.8 & 130 & 0 & 1,810 \\
\hline ContractSize & in mn. EUR & 2,659 & 3.25 & 16.2 & 0 & 445 \\
\hline \# Firms & & 521 & & & & \\
\hline
\end{tabular}

This table presents summary statistics for major variables used in the following estimations. The data originates from the Ifo Institute's Business Survey and a data set which comprises the universe of state export credit guarantee transactions provided by Euler Hermes.

obtain yearly data on firms' stock of tangible assets, the amount of working capital, and their cash flow from the Amadeus database. This information is available only for a subsample of firms. Furthermore, we obtain monthly averages of the interbanking rate (Euribor) charged on inter-bank loans with a duration of three months from Thomson Reuters Datastream. Table 2 summarizes the data for the estimation sample used in our preferred specification. ${ }^{32}$ Since we use six lags, observations start in July 2000.

\footnotetext{
${ }^{32}$ Table 7 in the Appendix sets out summary statistics for the full sample: they do not reveal any remarkable differences.
} 


\subsection{Empirical model}

Since our data are qualitative in nature, meaning that we observe the direction of the deviation in a firm's export sales but not the magnitude, we estimate a categorical choice model. ${ }^{33}$ Our observed variable is the firm's assessment of its stock of foreign orders relative to usual conditions which we code as follows:

$$
\Delta y_{i t}=\{1 \text { "larger than usual" }
$$

The latter three answering possibilities have been collapsed into one since, for reasons outlined below, the binary choice model is our preferred estimation strategy. The probability that firm $i$ reports a larger than usual stock of foreign orders at time $t$ is then given by

$$
\begin{aligned}
\mathrm{P}\left[\Delta y_{i t}=\right. & \left.1 \mid \mathbf{x}_{i t}\right]=\Gamma\left[\beta_{1} \text { Hermes }_{i t}+\beta_{1 k} \text { Hermes }_{i t}\right. \\
& \left.\times \text { FinCon }_{i t}^{k}+\beta_{\mathbf{3}}{ }^{\prime} \mathbf{X}_{i t}+\alpha_{t}+c_{i}\right],
\end{aligned}
$$

where $\alpha_{t}$ is a time fixed effect and $c_{i}$ is a firm fixed effect. We use a dummy variable, Hermes $_{i t} \in(0,1)$, that indicates whether a firm utilizes a guarantee at time $t$. Alternatively, we use the continuous measure ContractSize $e_{i t}$, the volume of the covered transaction, to measure the direct effect of a guarantee on exports. FinCon it $^{k}$ are the variables we interact with the Hermes indicator,

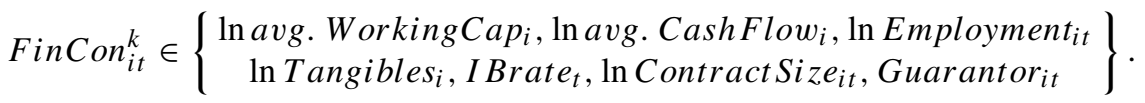

The first subset of interaction variables are proxies for firm $i$ 's dependence on external finance. We use the average level of its working capital (lnavg. WorkingCap ${ }_{i}$ ), or, alternatively, its cash flow (lnavg. CashFlowi), over the sample period to proxy for the amount of internal liquid funds available to the firm. In contrast to the stock at time $t$, the average level of liquid funds is not (or much less) reversely affected by changes in production and we expect it to be more indicative of general characteristics of the firm which imply availability of more or less liquid funds. As further proxies for a firm's dependence on external finance we use the firm's size, measured by $\ln$ Employment $_{i t}$, and its stock of tangible assets (In Tangibles T $_{i t}$ ). A larger stock of tangible assets reduces the riskiness of the firm as a borrower and hence, the risk component of the costs of external finance becomes less relevant.

The second subset of interaction terms comprises the variables we use to test whether Hermes guarantees are more important for those types of transactions which we expect to be more exposed to particular types of financial frictions. We use the interbanking rate $\left(\right.$ Ibrat $\left._{i t}\right)$ to test whether Hermes guarantees matter more in times of tighter refinancing conditions on the private financial market. The squared size of the covered loan (ln ContractSize $)_{i t}^{2}$ is included to assess whether larger transaction disproportionately benefit from coverage, which would be indicative of larger

\footnotetext{
${ }^{33}$ Ideally, we would perform the empirical analysis at the transaction level. However, linking the guarantee data to the survey is possible only at the firm level. We still expect to see the effects in the firm's assessment of its total export sales, albeit perhaps less pronounced.
} 
values at risk being harder to finance or insure through the private financial market. ${ }^{34}$ And finally, we use the importer's type of guarantor (Guarantor ${ }_{i t}$ ) as a proxy for the relative importance of the government's bargaining advantage in insolvency proceedings or debt renegotiations. We hypothesize that this advantage will be particularly relevant if a guarantor is involved and even more so if the guarantor is a foreign government or a foreign central bank.

The vector $\mathbf{X}_{i t}$ in Eq. 14 collects firm-level controls. It includes the firm's assessment of its demand conditions (Demand ${ }_{i t}$ ) as described in the data section. To account for the variable's categorical nature, we include it in the form of two binary indicator variables indicating a positive or a negative change. Coefficients on these indicators are thus to be interpreted as effects relative to the baseline category of "no change (demand as usual)." We include $l$ lags of the demand variable to capture demand shocks in the past. Since the demand variable is not specific to the firm's export situation, we also include its assessment of future exports (Expect Exp $\left.p_{i t}\right)$ and $m$ lags thereof to capture export-specific demand shocks. Our preferred estimation equation sets $l, m=6$. Increasing the number of lags turns out not to affect the results but reduces the size of the estimation sample. And finally, we include an interaction of our measures of external finance dependence with changes in the interbanking rate $\left(\Delta\right.$ Ibrat $\left._{t}\right)$ to control for the fact that firms which are more dependent on external finance are more affected by changes in the refinancing conditions of the private sector. Note that the direct effect of the interbanking rate is absorbed by the time fixed effect.

\subsection{Estimation strategies}

To estimate 14 parametrically, we make assumptions about the shape of the distribution function $\Gamma$. Our preferred estimation strategy is the probit model, which assumes that $\Gamma$ can be described by a normal distribution. The probit model requires for consistency that the firm fixed effects are uncorrelated with the regressors, thus implying a random effects model. It is possible to relax this assumption to some extent if the correlation can be specified explicitly. For example, if the fixed effects correlate only with the means of the regressors, then a Mundlak-Chamberlain-type probit model yields consistent parameter estimates. ${ }^{35}$ The corresponding assumption on the distribution of the firm fixed effect is

$$
c_{i} \mid \mathbf{X}_{i} \sim N\left(\overline{\mathbf{z}}_{i}^{\prime} \mathbf{b}, \sigma_{c}^{2}\right),
$$

where $\mathbf{X}_{i}=\left[\mathbf{X}_{i 1}, \ldots, \mathbf{X}_{i t}, \ldots, \mathbf{X}_{i T}\right]$ and $\overline{\mathbf{z}}_{i}$ denotes a vector of firm averages of the independent variables Hermes Hemand $_{i t}$, and ExpectExp Dever $_{i t}$ ove sample period. We also include sector fixed effects (on the two-digit level of the NACE 2002 classification) and averages of $\ln$ Employment $_{i}$ and the indicator variable

\footnotetext{
${ }^{34}$ When we test for the effect of squared contract size, we use contract size instead of the binary Hermes variable so that the direct effect of a larger covered volume is properly accounted for.

${ }^{35}$ C.p. Wooldridge's (2002) version of the approach proposed by Mundlak (1978) and generalized by Chamberlain (1980).
} 
Unconstrained $_{i}$ in $\overline{\mathbf{z}}_{i}$ to capture latent unobserved heterogeneity on the sector level, firm size, and the degree to which the firm is constrained in production, respectively. The Mundlak-Chamberlain probit model yields estimates of scaled coefficients. We describe in Appendix B.1 how marginal effects are computed. Robust standard errors are used to account for serial correlation due to the presence of latent heterogeneity. ${ }^{36}$

As an alternative estimation strategy we employ the conditional logit model. This model rests on the assumption that $\Gamma$ follows a logistic distribution. An important advantage of this model over the previous one is that it allows for unrestricted correlation of the unobserved fixed effect and the explanatory variables. However, it has disadvantages as well. Namely, for consistency, it requires that scores are uncorrelated over time. Another drawback that the logit model has in common with linear fixed effect estimation is that only firms exhibiting variation in the dependent variable over time are included. In contrast to the linear case, this confronts us with an additional problem when we intend to compute average partial effects or partial effects evaluated at sample means of the covariates, as this requires estimates of the $c_{i}$ 's for all firms in the sample. ${ }^{37}$ We thus view the results from the conditional logit estimation as robustness checks for the signs of our parameter estimates with respect to the orthogonality assumption that we have to make for the probit model, but do not compute partial effects.

Finally, as a further robustness check we estimate a linear probability model (LPM) with fixed effects. Here, the presence of arbitrary correlation between the $c_{i}$ 's and the explanatory variables, as well as serial dependence of scores, does not affect consistency of the parameter estimates.

\subsection{Identification}

Endogeneity concerns arise from the fact that both the decision to export and to apply for a guarantee are in parts jointly determined by time-varying demand conditions. In fact, for the type of guarantees considered here, firms apply on the basis of a welldefined project. Randomness of treatment is achieved by the fact that the total volume of guarantees granted by the government per year is limited by caps on the amount of risk assumed per country and in total and thus some applications are rejected. ${ }^{38} \mathrm{~A}$ natural counterfactual would thus be the firms whose applications have been rejected due to these statutory limits, but, unfortunately, this information is not available. ${ }^{39}$ Instead, we look at within-firm variation. The Ifo Business Survey is unique in that

\footnotetext{
${ }^{36}$ C.p. expression (15.53) in Wooldridge (2002).

${ }^{37}$ In principle, the $c_{i}$ 's can be backed out based on the data and consistent estimates of the other parameters. However, this is possible only for the firms included in the estimation. Hence, partial effects at the mean can be computed only at the mean value of the $c_{i}$ 's for the included firms. Computation of average partial effects would require specifying a distribution of the $c_{i}$ 's. Given that we explicitly allow for correlation between the $c_{i}$ 's and the right-hand-side variables, computations based on the mean or the empirical distribution of the $c_{i}$ 's of the included firms only do not constitute a satisfactory solution to this problem.

${ }^{38}$ For the period 2000 to 2010 , only about two thirds of the total value of coverage applications was granted.

${ }^{39}$ Furthermore, we would need to observe everything related to the feasibility and success rate of the project that was known to the agency when the decision was made, which is not very realistic either.
} 
it includes firms' monthly appraisal of demand conditions and export expectations. Hence, we are able to control for firms' demand situation with contemporary and lagged demand indicators. However, if changes in the stock of foreign orders reflect deviations in the demand situation beyond what we capture with the demand and export expectation variables and the numerous lags thereof, the issue of simultaneity persists.

Another potential issue is selection based on time-varying financial vulnerability of the firm. Firms facing tight credit conditions might be more likely to apply for a state credit guarantee. The firm's financial situation, however, also impacts export performance through the costs of finance and credit constraints. Such an effect would lead to a downward bias of the Hermes coefficient and therefore, our estimates are conservative in this respect.

For those reasons, the focus of our analysis does not lie on the estimated average effect of Hermes guarantees, but rather on the heterogeneity of the effect among firms that participate. To make sure that the economic interpretation of the interaction terms is meaningful, we have to rule out reverse influences of Hermes guarantees on the interaction variables. A concern regarding the interactions with the proxies for external finance dependence is that unusually high exports due to more beneficial financing conditions could adversely affect the firm's stock of liquid funds. To circumvent this reverse influence, which is a temporary effect, we use within-firm averages over the sample period. For our alternative proxies, ln Employment Ex $_{i}$ and $\ln$ Tangibles $_{i t}$, we would expect that these variable are, if at all, positively affected by higher than usual exports. Hence, a reverse influence would work in the opposite direction as our hypothesized relationships.

\subsection{Results}

\subsubsection{Baseline estimations}

Table 3 sets out the results of our baseline model for assessing the impact of a Hermes guarantee on the probability that a firm reports a "larger than usual" stock of foreign orders. The results in Column 1 are based on the most parsimonious specification to which we subsequently add further explanatory variables. Except for the production constraint indicator (avg. Unconstrained), we find significant estimates which point into the expected directions throughout the different specifications. The grant of a state credit guarantee has a positive effect on the probability that firms report higher than usual exports. Higher (lower) demand and export expectations today are associated with a higher (lower) than usual stock of foreign orders. When we add lags of those two variables ( 6 in Columns 2, 4-8 and 12 in Column 3), we find similar and statistically significant effects of demand conditions in the past. ${ }^{40}$ The effect of Hermes is very stable, notwithstanding the significant drop in observations that occurs due to the use of more lags. When we move from the pooled probit model to the

\footnotetext{
${ }^{40}$ For brevity's sake, these estimates are omitted from the table, but are available from the authors upon request.
} 


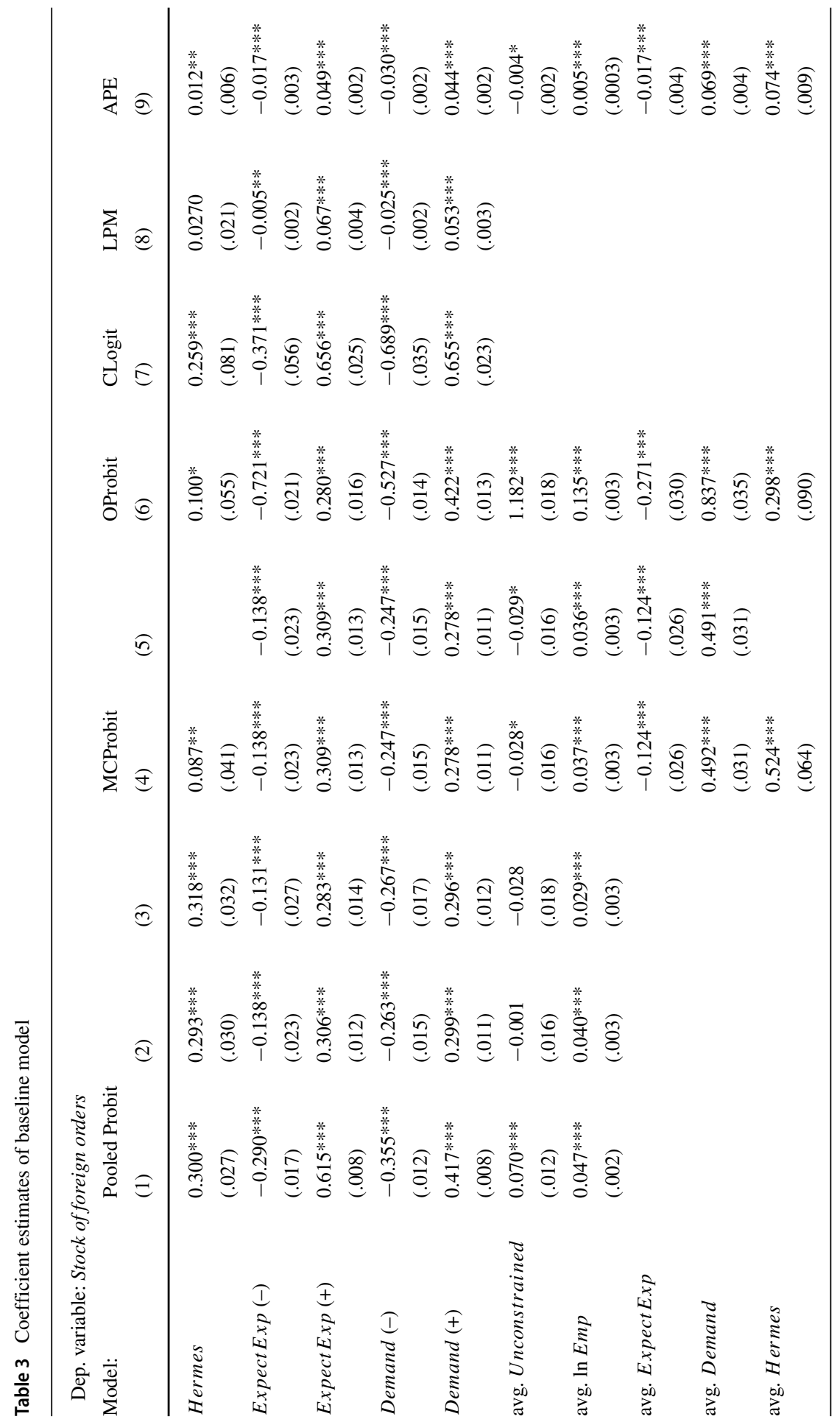




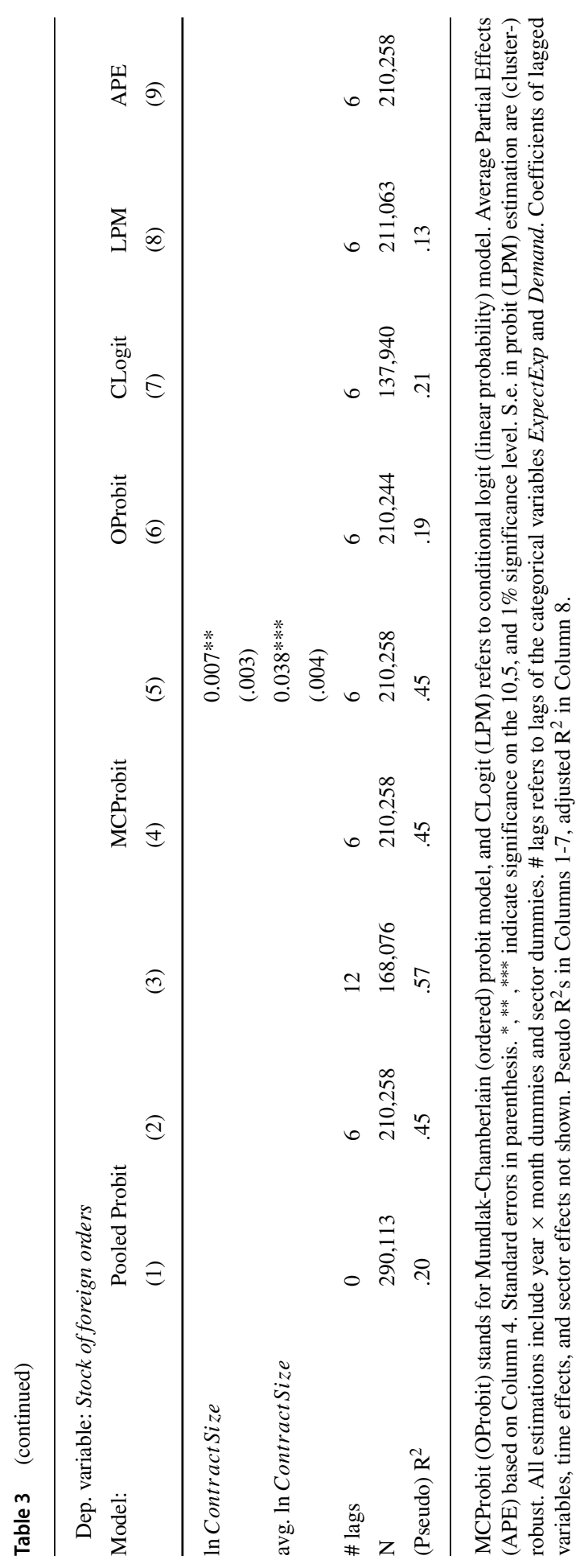


Mundlak-Chamberlain specification (Columns 4 and 5), the effect of Hermes drops from .3 to .08 and the average of the Hermes indicator is strongly significant. This suggests that firm fixed effects are important for capturing characteristics that determine both the firm's likelihood to use export credit guarantees scheme and report better than usual export conditions. In Columns 7 and 8 we present the results of the conditional logit estimation and the linear probability model with fixed effects, respectively. While the conditional logit model yields a highly significant and positive effect for Hermes, the LPM estimate is marginally not significant.

We find positive and significant effects of Hermes guarantees also if we use the $\log$ of the volume covered by the guarantee, ln ContractSize, instead of the indicator variable; see Column $5 .{ }^{41}$ We also estimate an ordered probit model with three categories of the variable stock of foreign orders ("better than usual", "as usual," and "worse than usual"). The results presented in Column 6 are very similar. Even though this specification uses more of the available information than does the binary probit, we still prefer the latter because the Brant test leads us to reject the parallel lines assumption underlying the ordered model. As pointed out above, pooled probit estimation of Eqs. 14 and 15 yields estimates of scaled coefficients. To assess the magnitude and economic significance of the effects we compute average partial effects as specified in Eqs. 17 and 18. Results for our preferred estimation specification (Column 4) are reported in Column 9. We find that the grant of a Hermes guarantee is associated with a 1.2 percentage point increase in the probability of reporting a higher stock of foreign orders. The average effect of better than usual demand conditions is 4.4 percentage points; a similar result holds for better than usual export expectations.

Taking our results together, we find support for a positive relationship between the use of guarantees and positive deviations from firms' normal stock of foreign orders. However, since potential simultaneity or selection issues cannot be ruled out entirely at this stage, we do not interpret the estimates as causal effects. Instead, we now focus on the heterogeneity of the effect with regard to characteristics of firms, insured transactions, or time periods to shed light on the channels through which these guarantees become effective.

\subsubsection{Heterogeneity of the effect of Hermes Guarantees}

Table 4 presents the results for parameter estimates of the interactions in our preferred baseline model as in Table 3, Column 4. We find significant interaction terms with the expected signs for all financial variables of interest. However, assessing the qualitative and quantitative effect as well as statistical significance of interacted variables in non-linear models is not straightforward, see, e.g., Ai and Norton (2003) and Greene (2010). As Greene (2010) points out, the sign of the interacted variable's coefficient is not necessarily the same as the sign of the actual interaction effect. Furthermore,

\footnotetext{
${ }^{41}$ Since we know only the duration of the coverage and the total volume, but not the volume per month, we distribute the total volume evenly across the months with coverage. Furthermore, we add a 1 to all observations exhibiting zero guaranteed volumns before taking logs. Due to these major but necessary modifications, this is not our preferred left-hand-side variable.
} 
Table 4 Interaction terms, coefficient estimates

Dependent variable: Stock of foreign orders

Model: Mundlak-Chamberlain Probit

(1)

(2)

(3)

(4)

(5)

(6)

\begin{tabular}{ll}
\hline Hermes & $1.102 * * *$ \\
& $(0.167)$ \\
$\times \ln$ Emp & $-0.152 * * *$ \\
& $(0.024)$
\end{tabular}

$\times$ Ibrate

$-0.491$

(.095)

$1.204 * * *$

$1.131 * * *$

$3.106 * * *$

(0.228)

(0.336)

(0.456)

(0.024)

$0.184 * * *$

$\times$ avg.

ln WorkingCap

(.026)

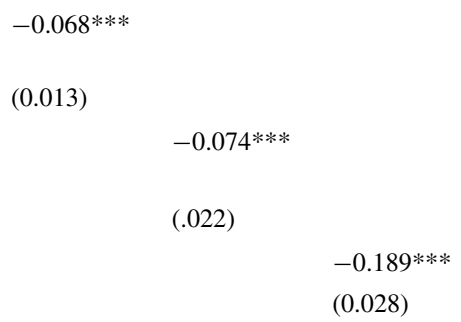

(0.013) $-0.074 * * *$

(.022)

$-0.189 * * *$

(0.028)

$\times \quad$ avg.

In CashFlow

$\times \ln$ Tangibles

$\Delta$ Ibrate

$\begin{array}{ll}\times \ln E m p & 0.018^{* * * *} \\ & (0.002)\end{array}$

$\times \quad$ avg.

In WorkingCap
$\times \quad$ avg.
In CashFlow

$\times \ln$ Tangibles

avg. $\ln E m p$

$\begin{array}{llllll} & & & & -0.003 \\ & & & \\ & & & & \\ & & & & & \\ 0.035^{* * *} * & 0.036 * * * & 0.036^{* * *} & 0.001 & 0.040 * * * & 0.037 * * * \\ (0.003) & (.003) & (.004) & (.005) & (.006) & (.003) \\ & & & & & \end{array}$

$$
0.007 * * *
$$

(0.001)

$-0.005^{* *}$

(0.002)

avg.

ln WorkingCap

(0.002)

avg. In CashFlow

$0.017 * * *$

(0.004)

ln Tangibles

$-0.004$

(0.004)

In Contract Size

$-0.076 * * *$

(.019)

$0.006^{* * *}$

$\times \ln$ Contract Size

(.001) 
Table 4 (continued)

Dependent variable: Stock of foreign orders

Model: Mundlak-Chamberlain Probit

(1)

(2)

(3)

(4)

(5)

(6)

\begin{tabular}{lllllll}
\hline $\mathrm{N}$ & 210,258 & 210,258 & 114,209 & 92,989 & 65,352 & 210,258 \\
Pseudo $\mathrm{R}^{2}$ & .45 & .45 & .70 & .75 & .82 & .45 \\
\hline
\end{tabular}

Estimations are based on the specification in Table 3, Column 4. Robust standard errors in parenthesis. $*, * *, * * *$ indicate significance on the 10,5 , and $1 \%$ significance level. Coefficients of lagged variables, firm averages (except for direct effects of interacted variables), time and sector FE not shown

regarding inference, $\beta_{1 k}=0$ is not sufficient for the interaction effect to be zero. In fact, various combinations of estimated parameters and the data can equate it to zero. Hence, the standard statistical inference results for marginal effects are difficult to interpret economically. Greene (2010) suggests looking at predicted probabilities at different values of the covariates instead. We follow his advice and assess the heterogeneity of the effect of Hermes by graphically analyzing differences in predicted probabilities between firms with and without a guarantee at different levels of the covariates. $^{42}$

The role of financing conditions. We consider first the hypothesis that firms depending more on external finance benefit more from the use of a state credit guarantee. As detailed above, we use information on cash flow, working capital, firm size measured by employment, and tangible assets to proxy for external financial dependence. For all measures we find the expected interaction effect. The four panels in Fig. 4 plot the predicted probabilities of reporting a higher than usual stock of foreign orders for firms with and without a guarantee. The difference between the two curves reflects the marginal effect of Hermes. Shaded bands indicate 90 percent confidence intervals. As the respective panels in Figure 4 illustrate, the effect of a Hermes guarantee is stronger for small firms and firms with little working capital, small average cash flows, and small stocks of tangible assets. This suggests that Hermes guarantees unfold their effects at least partly by lowering firms' cost of external finance.

Next, we analyze the role played by the private financial sector's refinancing conditions. We find support for the hypothesis that Hermes guarantees have a stronger effect when refinancing costs are high, which lends support to the hypothesis that costs of liquidity management reduce private financial agents' willingness to take on the risk involved in these transactions. Figure 5 shows that the marginal effect

\footnotetext{
${ }^{42}$ Significance of the coefficient estimates is, of course, still important as it influences the precision of the predicted probabilities.
} 

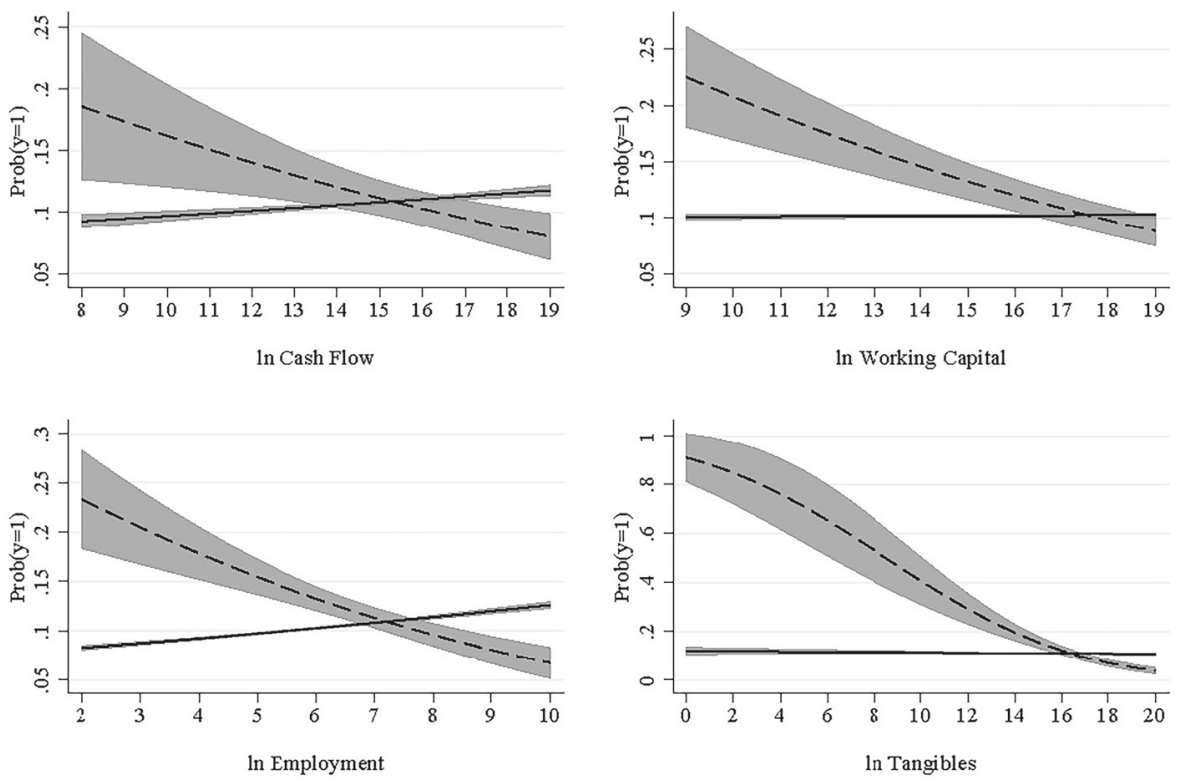

- - - He:mes $=1 \quad$ Hermes $=0$

Fig. 4 External Finance Dependence. The figure shows means of predicted probabilities and $90 \%$ confidence intervals computed at various levels of four measures of external finance dependence

of Hermes becomes larger (in absolute terms) for higher values of the interbanking rate. $^{43}$

We also test whether changes in the private financial sector's refinancing conditions affect firms with high demand for external finance more by interacting the change in the interbanking rate ( $\Delta$ Ibrate $)$ with the proxies for firms' dependence on external finance. We find positive interaction effects for employment and working capital, suggesting that larger firms and firms with more liquid funds cope better with tighter refinancing conditions. See Fig. 7 in the Appendix for plots of the predicted probabilities across different levels of the external finance variables at the 25th, 50th, and 75th percentile of $\Delta$ Ibrate. Those results highlight the sensitivity of firms' exports to lending conditions on private financial markets.

Characteristics of the insured contract. To evaluate the hypothesized cost advantages of the state credit guarantee scheme in providing credit guarantees for large values at risk we assess the effect of the covered volume and, in particular, its non-linearity. We hypothesize that both the costs of risk diversification and the coordination costs of private financiers are higher for larger values at risk and hence, large

\footnotetext{
${ }^{43}$ At first glance, it might be puzzling that both probabilities are upward sloping. However, note that the direct effect of the interbanking rate is absorbed in the time fixed effects and thus does not feature in our predictions.
} 


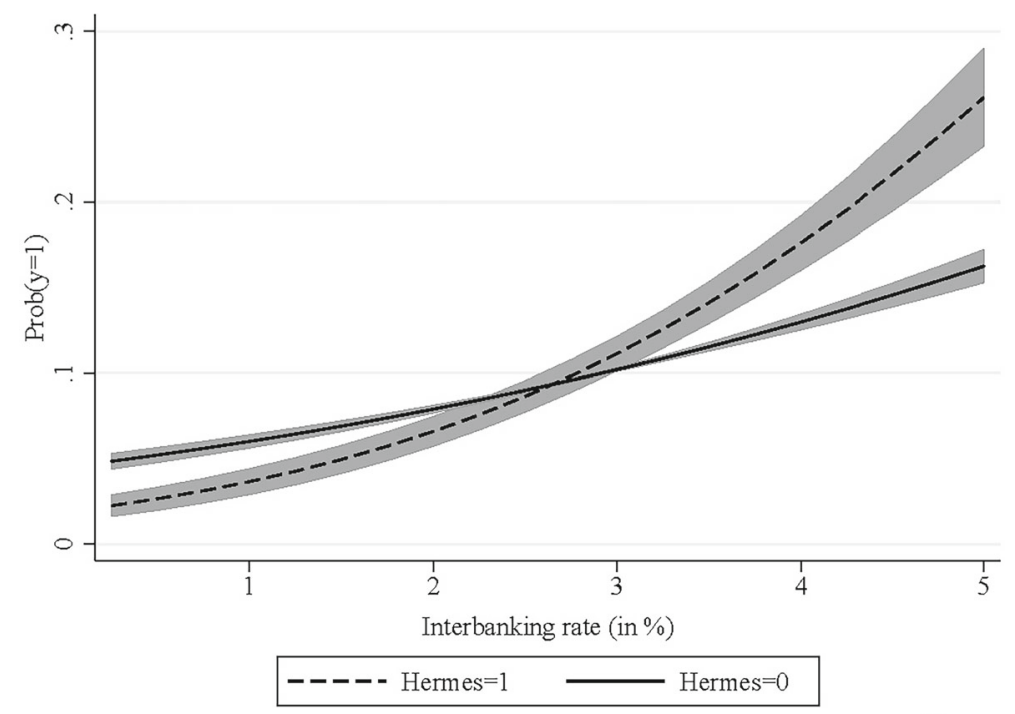

Fig. 5 Interbanking Rate. The figure shows the mean of predicted probabilities and $90 \%$ confidence intervals computed at various levels of the interbanking rate

transaction should benefit disproportionately from the presence of Hermes guarantees. To test this presumption we add the squared volume of the covered transaction (ln ContractSize $)^{2}$ and look at predicted probabilities for Hermes firms at different contract sizes (Fig. 6). The horizontal line depicts the predicted probability for firms

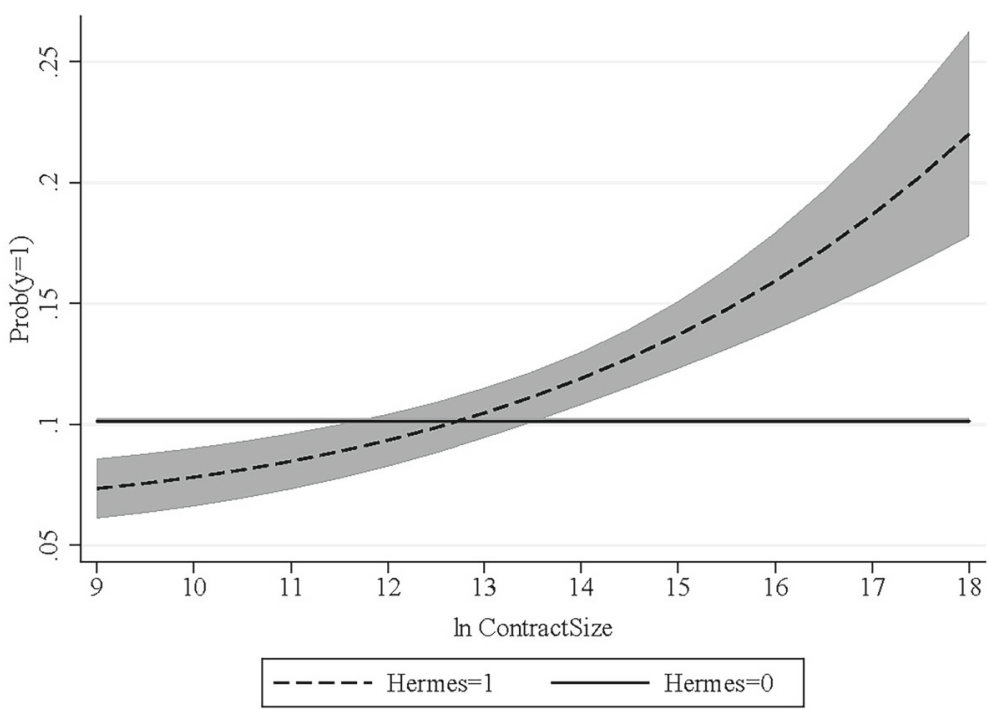

Fig. 6 Contract Size. The figure shows the mean of predicted probabilities and $90 \%$ confidence intervals computed at various levels of the log contracted guarantee volumes 
Table 5 Type of the importer's guarantor

\begin{tabular}{llll}
\hline & $\widehat{\operatorname{Pr}}(y=1 \mid X)$ & $90 \% \mathrm{CI}$ & $\#$ obs \\
\hline $\begin{array}{l}\text { Hermes }=0 \\
\text { Hermes }=1\end{array}$ & .102 & {$[.101 ; .103]$} & 207712 \\
State & .079 & & \\
Bank & .121 & {$[.045 ; .112]$} & 59 \\
Private & .164 & {$[.095 ; .148]$} & 199 \\
None & .105 & {$[.138 ; .191]$} & 361 \\
\hline
\end{tabular}

Predicted probabilities, based on the specification in Table 3, Column 4

without Hermes. For firms using guarantees, the predicted probability is increasing in contract size. This reflects the direct effect. Moreover, the predicted probability is convex in the size of covered transaction, suggesting that also the marginal effect of coverage is increasing in contract size.

Finally, we look for evidence for the hypothesis that the government's stronger bargaining power in debt renegotiation or insolvency proceedings endows it with a cost advantage in providing guarantees. We use information on the importer's type of guarantor to assess this prediction, assuming that bargaining power is particularly important for contracts where the importer has a guarantor as well and even more so if the foreign government or the foreign central bank is involved. Our results presented in Table 5 are mixed: We find that the predicted probability compared to firms without a guarantee is significantly higher in cases where the importer has a private guarantor, but smaller (yet not significantly so) in cases where the guarantor is the foreign state or central bank. ${ }^{44}$

\subsubsection{Robustness checks}

As robustness analysis, we estimate all the specifications using in a linear probability model where the coefficients on the interaction terms can straightforwardly be interpreted as interaction effects. The estimated coefficients are presented in Table 6. We find our results from the Mundlak-Chamberlain probit model confirmed with regard to the signs of the interactions effects, although significance is weaker. The interactions with ln WorkingCapital, ln Tangibles, and (ln ContractSize) ${ }^{2}$ are no longer significant. For the interactions with $\Delta$ Ibrate we find significant interaction effects for all the financial variables. We also estimate a conditional logit model and find significant interaction terms except for (ln ContractSize $)^{2}$. Table 9 in the Appendix presents the results.

\footnotetext{
${ }^{44}$ Estimation of these interactions is likely hampered by the fact that we pool guaranteed transactions with potentially different guarantor types that take place at the same point in time. This is necessary because our dependent variable is at the firm level and not at the transaction level.
} 
Table 6 Interaction terms, linear probability model

Dep. variable: Stock of foreign orders

Model: Linear Probability Model with FE

(1)

Hermes
$\times \ln$ Emp
$\times$ Ibrate
$\times$ avg. ln WorkingCap
$\times$ avg. ln CashFlow
$\times \ln$ Tangibles

$\Delta$ Ibrate

$\times \ln$ Emp
$\times$ avg. $\ln$ WorkingCap
$\times$ avg. $\ln$ CashFlow
$\times \ln$ Tangibles

ln ContractSize

$\times \ln$ ContractSize

$0.173^{* *}$
$(.084)$
$-0.022^{*}$
$(.012)$

$0.066 * * *$

(.013)

$-0.003$

(.006)

$$
\begin{aligned}
& -0.023 * * * \\
& (.008)
\end{aligned}
$$

$(.011)$

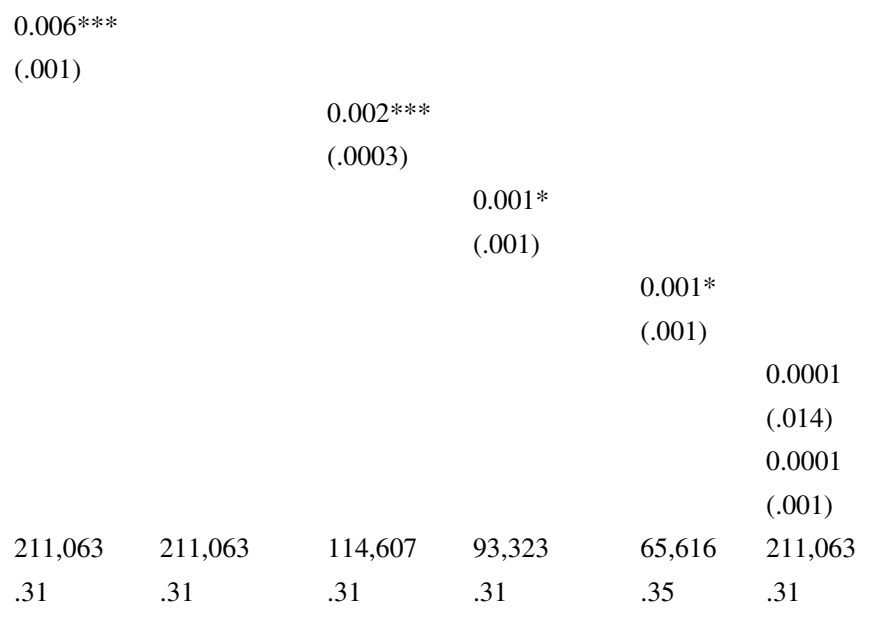

LPM with firm fixed effects. Standard errors clustered on firm level in parenthesis. ${ }^{*},{ }^{* *},{ }^{* * *}$ indicate significance on the 10,5, and $1 \%$ significance level. Coefficients of covariates and time FE not shown

The major movements in the interbanking rate during our sample period occurred around the global financial crisis of 2008. The Euribor 3-months rate increased from about 2 to 5 percent in the build-up of the crisis and dropped down to below 1 percent thereafter. Hence, the estimated positive interaction between coverage indicator and the interbanking rate may reflect a disproportionately positive effect of coverage during the crisis. In fact, Felbermayr et al. (2012) find larger than average effects of coverage on employment and sales during the years 2008 and 2009. 
To analyze whether the financial crisis had an effect on the effectiveness of the guarantees beyond its impact on the interbanking rate, we ran an additional specification including an interaction between Hermes and a dummy for the crisis period on top of the interaction with the interbanking rate. The estimated interaction with the crisis indicator turns out insignificant, suggesting no impact of the crisis on the effectiveness of the guarantees beyond the crisis' impact on refinancing conditions of the banking sector.

\section{Conclusion}

In this paper, we analyze the effect of German state export credit guarantees ("Hermes guarantees") on firms' exports. This policy instrument is commonly justified by politicians as a means to mitigating negative consequences of financial market frictions for exporting firms and, indeed, previous research finds evidence of a positive relationship. However, due to lack of appropriate data, evidence on the channels through which the policy instrument really works is scarce, even though this is crucial for the welfare implications of the state intervention and for the instrument's efficient design.

More than 60 years of data on the profit and loss account of the state credit guarantee scheme suggest that the program operates profitably, that is, the premia demanded in return for the guarantees have made up for the losses that have been incurred over time. Financial market frictions are thus an obvious explanation for the absence of similar insurance products on private financial markets. We analyze potential market imperfections and characteristics of the state that could rationalize a cost advantage of a public credit guarantee scheme in providing guarantee for particular types of risky transactions.

Against the backdrop of a financial market where agents are faced with liquidity risk and regulation aimed at enforcing solvency at all times, we propose that the state's "deep pocket" endows it with cost advantage in financing or guaranteeing projects involving large values at risk. We also suggest that the government might be more efficient in recovering claims when guarantees are drawn due to greater bargaining power and lower coordination cost in the case that a share of the claim can be recovered through debt renegotiation or insolvency proceedings.

We test these hypotheses using a unique firm-level data set that results from joining data on German state credit guarantees, granted to firms between 2000 and 2010, with the Ifo Business Survey. Our main findings are that Hermes guarantees have a positive effect on firms' export performance and especially so for small firms and firms that are more dependent on external finance. Financing conditions on private financial markets also matter for the strength of the effect, suggesting that cost of liquidity are a relevant factor. Moreover, for guarantees covering large transactions we find a particularly strong effect, which can be rationalized with transaction costs of risk diversification for private financial agents and/or costs of coordination among creditors in case of debt renegotiation or insolvency proceedings. Our results thus lend support to the hypothesis that the positive effect of Hermes guarantees on exports manifests itself by mitigating financial constraints. 
We conclude with a note on the generality of our findings. The theoretical mechanisms and arguments outlined in this paper apply in a similar manner to firm choices other than the extensive and intensive margins of exports. The need to obtain upfront finance for projects that are risky and large compared to a firm's size is inherent to many investment opportunities. Accordingly, public credit guarantees can also be obtained for foreign direct investment. An exploration of the generality of our empirical findings to other dimensions of firms' internationalization choices is left for future research.

Acknowledgments We thank participants of the seminar at the University of Munich, the University of Aarhus, the EGIT, the ETSG annual meeting, the ifo/CEPII/GEP conference in Ningbo, the CESifoDelphi conference, and the Auckland Finance Meeting. Special thanks go to Gabriel Felbermayr, Timothy Riddiough, Kalina Manova, Georg Schaur, Tim Schmidt-Eisenlohr, Marc Auboin, Hans-Werner Sinn, Ben Moll, Banu Demir Pakel, Joachim Wagner, Mathias Hoffmann, Gary Hufbauer, and Friederike Niepmann for helpful discussions and suggestions. Inga Heiland gratefully acknowledges funding from the European Research Council under the European Union's Horizon 2020 research and innovation program (grant agreement 715147). Our dataset is built from three different sources which are subject to restricted access of different degrees. The Ifo business survey data is subject to data protection regulation and can only be accessed on-site at the LMU-ifo Economics \& Business Data Center (https:/www.cesifo-group.de/ ifoHome/facts/EBDC.html). Furthermore, export credit guarantee information is confidential registry data under the auspice of the ministry of economics. Finally, the fim-level data from the Amadeus database is proprietary (https://amadeus.bvdinfo.com).

Funding Open Access funding enabled and organized by Projekt DEAL.

Open Access This article is licensed under a Creative Commons Attribution 4.0 International License, which permits use, sharing, adaptation, distribution and reproduction in any medium or format, as long as you give appropriate credit to the original author(s) and the source, provide a link to the Creative Commons licence, and indicate if changes were made. The images or other third party material in this article are included in the article's Creative Commons licence, unless indicated otherwise in a credit line to the material. If material is not included in the article's Creative Commons licence and your intended use is not permitted by statutory regulation or exceeds the permitted use, you will need to obtain permission directly from the copyright holder. To view a copy of this licence, visit http://creativecommons.org/licenses/by/4.0/.

\section{Appendix}

\section{A Proofs}

\section{A.1 Proof of Result 1}

For a given financing mode $o^{\prime} \in(B, G), \frac{\partial r[a]}{\partial R^{o^{\prime}}}<0$, optimal sales fall if the firm is operating under mode $o^{\prime}$ and does not switch to $o \neq o^{\prime}$, or if it switches the mode and had not been indifferent in the initial situation. If the firm is operating under mode $o$ or if it was indifferent in the initial situation, optimal sales remain unchanged.

Let RHS denote the right-hand side of Eq. 7. Since $f>k, \frac{\partial R H S}{\partial R^{o \prime}}>0$ and since $\frac{\partial r\left[\bar{a}^{o \prime}\right]}{\partial\left(1 / \bar{a}^{\prime \prime}\right)}>0,1 / \bar{a}^{o^{\prime}}$ increases as $R^{o^{\prime}}$ increases. The threshold productivity that is relevant for the firm increases unless it is operating under $o \neq o^{\prime}$ or was indifferent in the initial situation.

Since $\frac{\partial^{2} R H S}{\partial R^{o \prime} \partial k}<0$, the adjustment in $1 / a^{o \prime}$ is stronger the smaller $k$. 


\section{A.2 Proof of Results 2 \& 3.}

For $o \in[B, G]$,

$$
\begin{aligned}
\frac{\partial R^{o}}{\partial \bar{R}} & =\frac{1}{\rho^{o}}-\frac{1}{\left(\rho^{o}\right)^{2}} \frac{\partial \rho^{o}}{\partial \bar{R}}>0 \quad \text { since } \quad \frac{\partial \rho^{o}}{\partial \bar{R}}=-c^{o}(1-\lambda)\left(1-b^{o}\right)<0 \\
\frac{\partial R^{o}}{\partial \lambda} & =-\frac{\bar{R}}{\left(\rho^{o}\right)^{2}} \frac{\partial \rho^{o}}{\partial \lambda}<0 \quad \text { since } \quad \frac{\partial \rho^{o}}{\partial \lambda}=\left(1-b^{o}\right)\left(1+\bar{R} c^{o}\right)>0 \\
\frac{\partial R^{o}}{\partial c^{o}} & =\frac{\bar{R}^{2}}{\left(\rho^{o}\right)^{2}}(1-\lambda)\left(1-b^{o}\right)>0 \\
\frac{\partial R^{o}}{\partial b^{o}} & =-\frac{\bar{R}^{2}}{\left(\rho^{o}\right)^{2}}\left[(1-\lambda)\left(1+\bar{R} c^{o}\right)\right]<0 \\
\frac{\partial^{2} R^{o}}{\partial c^{o} \partial \bar{R}} & =\frac{2 \bar{R}}{\left(\rho^{o}\right)^{2}}(1-\lambda)\left(1-b^{o}\right)\left[1-\frac{\partial \rho^{o}}{\partial \bar{R}} \frac{\bar{R}}{\rho^{o}}\right]>0 \\
\frac{\partial^{2} R^{o}}{\partial c^{o} \partial \lambda} & =-\frac{\bar{R}^{2}}{\left(\rho^{o}\right)^{2}}\left(1-b^{o}\right)\left[\frac{2}{\rho^{o}} \frac{\partial \rho^{o}}{\partial \lambda}(1-\lambda)+1\right]<0 \\
\frac{\partial^{2} R^{o}}{\partial b^{o} \partial \bar{R}} & =\frac{\bar{R}}{\left(\rho^{o}\right)^{2}}(1-\lambda)\left[\frac{2 \bar{R}}{\rho^{o}}\left(1+\bar{R} c^{o}\right) \frac{\partial \rho^{o}}{\partial \bar{R}}-2-3 \bar{R} c^{o}\right]<0 \\
\frac{\partial^{2} R^{o}}{\partial b^{o} \partial \lambda} & =\frac{\bar{R}^{2}}{\left(\rho^{o}\right)^{2}}\left(1+\bar{R} c^{o}\right)\left[\frac{2}{\rho^{o}} \frac{\partial \rho^{o}}{\partial \lambda}(1-\lambda)+1\right]>0 .
\end{aligned}
$$

\section{B Empirical Appendix}

\section{B.1 Average Partial Effects and Predicted Probabilities}

Table 7 Summary statistics of full sample

\begin{tabular}{lllllll}
\hline Full sample & & Obs & Mean & Std. Dev. & Min & Max \\
\hline Stock offor. orders & binary & 326,201 & 0.09 & 0.29 & 0 & 1 \\
Demand & ordinal & 327,805 & 1.99 & 0.65 & 1 & 3 \\
Employment & & 328,052 & 2,102 & 14,555 & 1 & 200,000 \\
ExpectExp & ordinal & 293,505 & 2.07 & 0.54 & 1 & 3 \\
Unconstrained & binary & 325,942 & 1.60 & .30 & 1 & 2 \\
Ibrate & in \% & 328,053 & 2.98 & 1.32 & 0.64 & 5.11 \\
WorkingCap & in bn. EUR & 91,636 & 38.6 & 136 & $-1,290$ & 2,550 \\
CashFlow & in bn. EUR & 79,035 & 29.8 & 167 & $-1,130$ & 4670 \\
Tangibles & in bn. EUR & 100,756 & 43.9 & 247 & 0 & 10,600 \\
ContractSize & in mn. EUR & 3,183 & 3.02 & 15.1 & 0 & 445 \\
\# Firms & & 5,741 & & & & \\
with Hermes & & 684 & & & & \\
\hline
\end{tabular}


Table 8 Translated survey questions and answers

\begin{tabular}{|c|c|c|c|c|}
\hline Variable & $\begin{array}{l}\text { Variable name } \\
\text { in original dataset }\end{array}$ & Question/answer & Coding & $\begin{array}{l}\text { Alternative } \\
\text { coding }\end{array}$ \\
\hline \multirow[t]{5}{*}{ Stock of for. orders } & foreord & $\begin{array}{l}\text { Our current stock of for- } \\
\text { eign orders is }\end{array}$ & & \\
\hline & & larger than usual & 3 & 1 \\
\hline & & $\begin{array}{l}\text { sufficient (as } \\
\text { usual (for the } \\
\text { season)) }\end{array}$ & 2 & 0 \\
\hline & & too small & 1 & 0 \\
\hline & & we do not export & - & 0 \\
\hline \multirow[t]{7}{*}{ ExpectExp } & expexp & $\begin{array}{l}\text { Considering settled deals } \\
\text { and deals }\end{array}$ & & \\
\hline & & $\begin{array}{l}\text { under negotiation, we } \\
\text { expect exports }\end{array}$ & & \\
\hline & & (in the next three months) to & & \\
\hline & & increase & 3 & \\
\hline & & stay the same & 2 & \\
\hline & & decrease & 1 & \\
\hline & & we do not export & - & \\
\hline \multirow[t]{4}{*}{ Demand } & demand_vpq & $\begin{array}{l}\text { (Last month's tendency) } \\
\text { The demand } \\
\text { situation has }\end{array}$ & & \\
\hline & (before 11/2001 & improved & 3 & \\
\hline & “demand”) & not changed & 2 & \\
\hline & & worsened & 1 & \\
\hline \multirow[t]{3}{*}{ Unconstrained } & constrain & $\begin{array}{l}\text { Our domestic production } \\
\text { activity right } \\
\text { now is constrained }\end{array}$ & & \\
\hline & & no & 2 & \\
\hline & & yes & 1 & \\
\hline
\end{tabular}

Explanations in brackets were given to firms as supplementary information on how the questions are to be interpreted

The Mundlak-Chamberlain probit model yields estimates of scaled coefficients, $\hat{\beta}_{h a}=\hat{\beta}_{h} \frac{1}{\left(1+\sigma_{c}\right)^{1 / 2}}$ and $\hat{b}_{h a}=\hat{b}_{h} \frac{1}{\left(1+\sigma_{c}\right)^{1 / 2}}$. These scaled coefficients are sufficient to compute average partial effects and predicted probabilities. ${ }^{45}$ Predicted probabilities can be computed as

$$
\widehat{\mathrm{P}}\left[\Delta y_{t}=1\right]=\frac{1}{N} \sum_{i=1}^{N} \Phi\left(\left(\mathbf{x}_{i t}^{\prime} \hat{\beta}+\hat{c}_{i}\right) \frac{1}{\left(1+\sigma_{c}\right)^{1 / 2}}\right)=\frac{1}{N} \sum_{i=1}^{N} \Phi\left(\mathbf{x}_{i t}^{\prime} \hat{\beta}_{a}+\overline{\mathbf{z}}_{i}^{\prime} \hat{\mathbf{b}}_{a}\right),
$$

\footnotetext{
${ }^{45}$ C.p. also Wooldridge (2002) [p. 488] for a detailed discussion.
} 


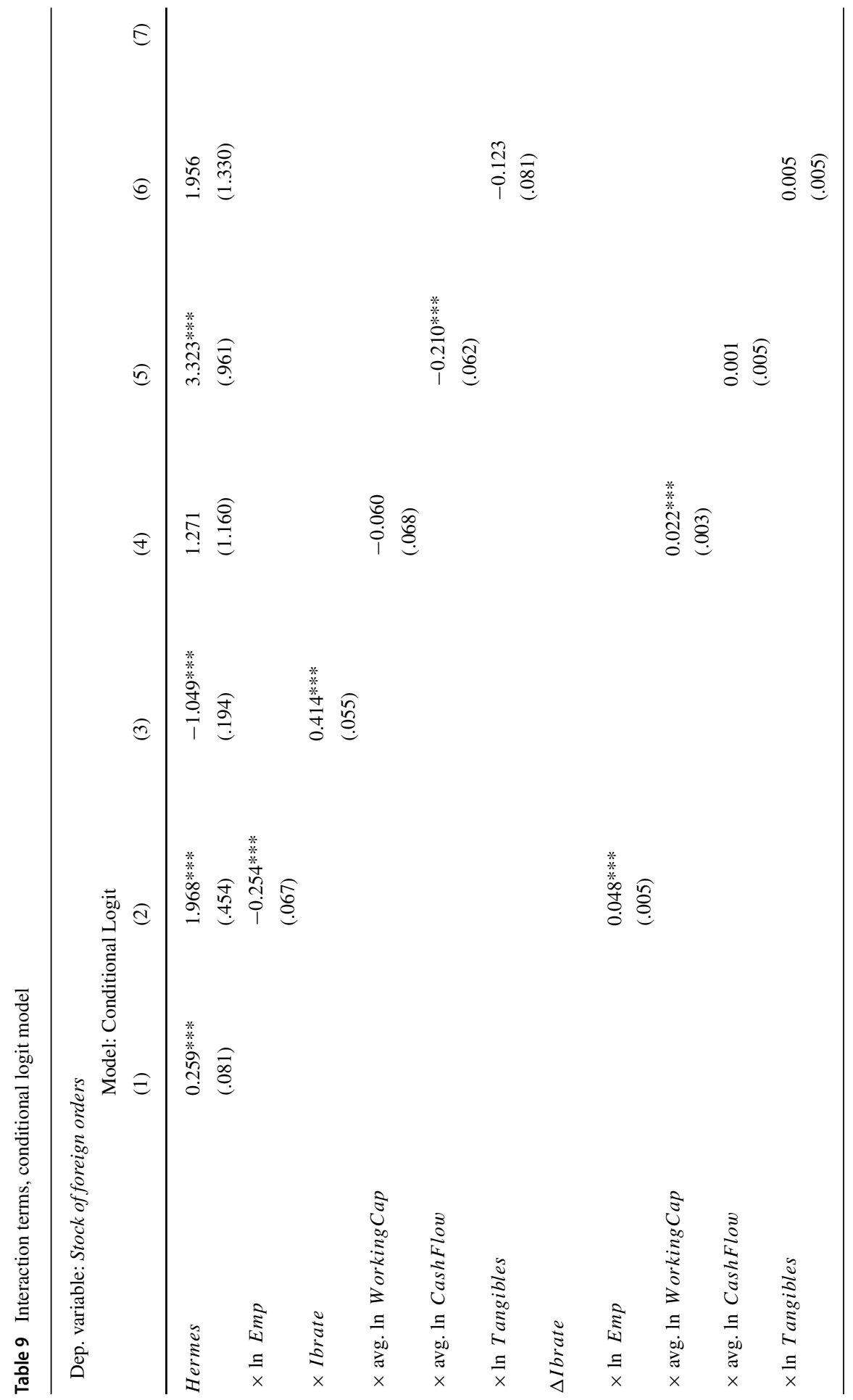




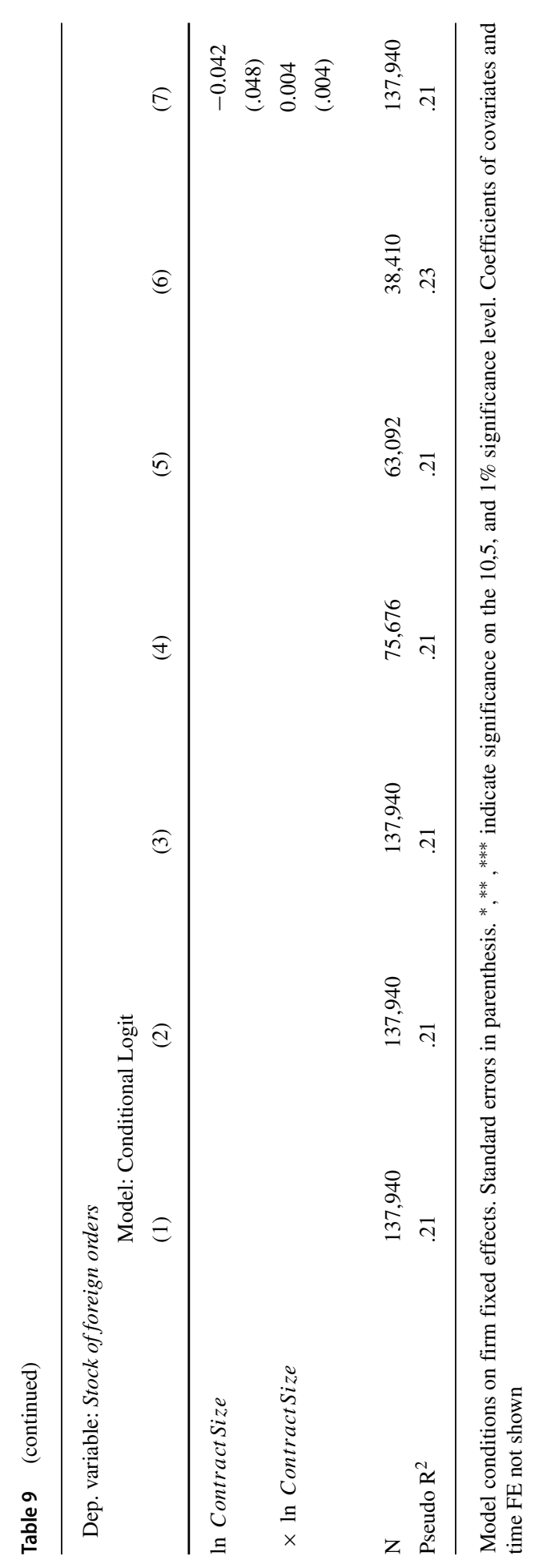



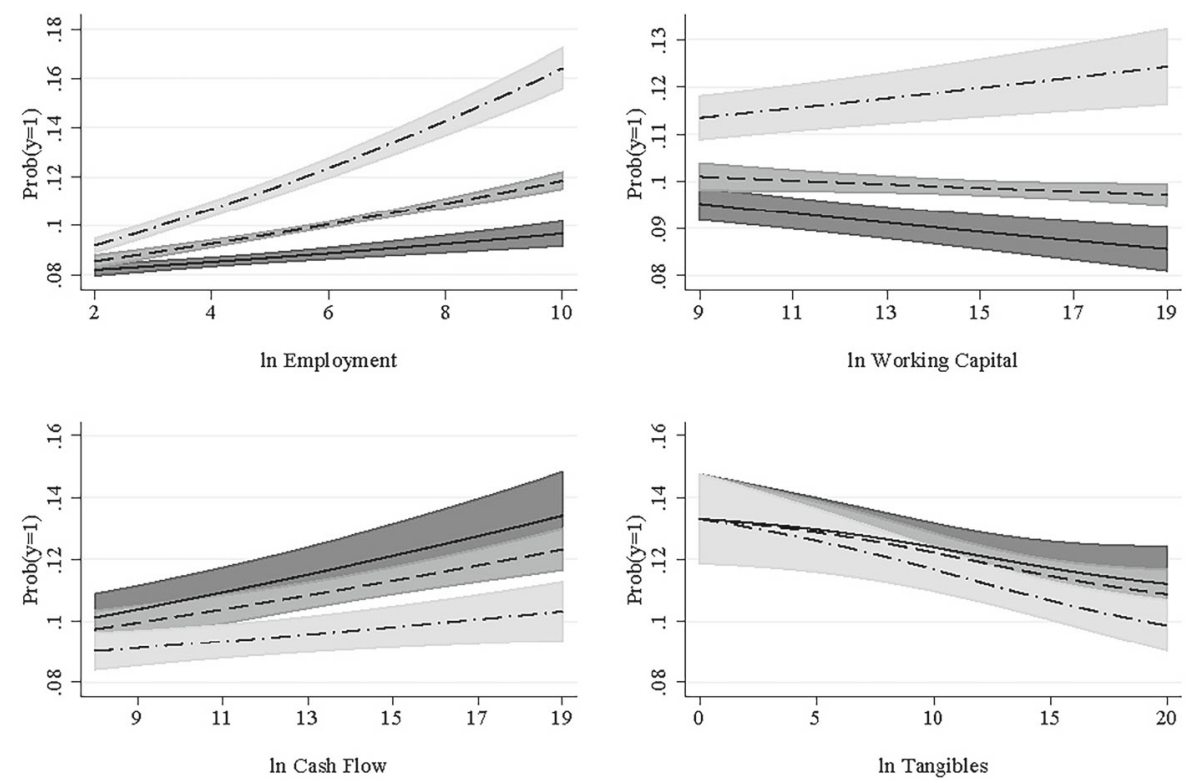

D.Ibrate $\mathrm{p}(25)=-.85 \quad-\quad$ D.Ibrate $\mathrm{p}(50)=-.45 \quad-\cdot-$ D.Ibrate $\mathrm{p}(75)=.93$

Fig. 7 External Finance Dependence and Changes in the Interbanking Rate. The figure shows means of predicted probabilities and $90 \%$ confidence intervals computed at different levels of four measures of external finance demand and the 25th, 50th, and 75th percentile of the distribution of changes in the interbanking rate

where $\mathbf{x}_{i t}^{\prime} \hat{\beta}=\hat{\beta}_{1}$ Hermes $_{i t}+\hat{\beta}_{1 k}$ Hermes $_{i t} \times$ FinCon $_{i t}^{k}+\hat{\beta}_{\mathbf{3}}{ }^{\prime} \mathbf{X}_{i t}+\hat{\alpha}_{t}$. The average partial effect (APE) of a binary covariate $x_{h}$ is given by

$$
\widehat{\mathrm{dP}}[\Delta y=1]=\frac{1}{N T_{i}} \sum_{i=1}^{N} \sum_{t=1}^{T_{i}}\left(\widehat{\mathrm{P}}\left[\Delta y_{i t}=1 \mid x_{i t, h}=1\right]-\widehat{\mathrm{P}}\left[\Delta u y_{i t}=1 \mid x_{i t, h}=0\right]\right),
$$

and the average partial effect of a continuous covariate $x_{h}$ is given by

$$
\frac{\partial \widehat{\mathrm{P}}[\Delta y=1]}{\partial x_{h}}=\frac{1}{N T_{i}} \sum_{i=1}^{N} \sum_{t=1}^{T_{i}} \hat{\beta}_{a h} \phi\left(\mathbf{x}_{i t}^{\prime} \hat{\beta}_{a}+\overline{\mathbf{z}}_{i}^{\prime} \hat{\mathbf{b}}_{a}\right) .
$$

$\phi$ and $\Phi$ denote the probability density function and cumulative density function of the standard normal distribution, respectively. $T_{i}$ is the number of observations of firm $i$ over time. Standard errors are obtained with the Delta method. Details can be found, for example, in Chapter 2.6.4 in Greene and Henscher (2010). 


\section{C: Generalization of the Model}

In the following, we prove that a qualitatively similar but weaker form of Result 1 holds if we dispense with the simplifying assumptions made in Section 3, where we considered only the case when external finance is more costly than internal finance, $\lambda R^{o}>\bar{R}$, and the firm's liquid funds are small, $k<f$. In the general case, the firm chooses the optimal price, the size of the loan $L=\ell+\gamma G$ (including the guarantee costs), and the degree of coverage $g$. Let $g$ denote the share of the loan that is covered (without the interest payment). Then, the amount of coverage purchased (as defined above in Section 3.4) is $G=\bar{R} g .{ }^{46}$ The maximization problem is then

$$
\begin{aligned}
\max _{p, \ell, g} \pi=\lambda p q-(a q+f)+\ell- & \lambda \bar{R} g-\lambda R^{B}(\ell+\gamma \bar{R} g-g)+(\bar{R}-1)(\ell-a q-f) \\
\text { s.t. } \quad \ell+k & \geq a q+f \\
p q & \geq R^{B}(\ell+\gamma \bar{R} g-g)+\bar{R} g \\
g & \geq 0 \\
\ell+\gamma \bar{R} g & \geq g
\end{aligned}
$$

and subject to demand as in Eq. 1. In the first period, the firm pays production costs, receives the loan $\ell+\gamma G$ and pays $\gamma G$ for the guarantee (leaving the firm with net borrowed funds of $\ell$ ). In the second period, with probability $\lambda$ it receives the value of its sales, and with probability $(1-\lambda)$ the importer defaults and the guarantee pays off in the amount $\bar{R} g$. Furthermore, the firm pays back the bank; with certainty the covered share plus interest $G=\bar{R} g$ (leaving the firm with a net expected payment of $\lambda G)$ and with probability $\lambda$ the uncovered part plus interest $R^{B}(L-g)$ as well. Moreover, the firm receives interest $\bar{R}-1$ from investing its remaining liquid funds $\ell+k-(a q+f)$. Finally, it substracts the opportunity costs $(\bar{R}-1) k$ of the investment, which it could have undertaken instead of the export project. ${ }^{47}$

The financing constraint (C.2) requires that the firm's total means suffice to cover total costs. The borrowing constraint (C.3) states that the total payment for the project-specific loan cannot exceed the volume of the project. The third constraint requires that the covered amount is non-negative and finally, the fourth constraint

\footnotetext{
${ }^{46}$ While the distinction between $g$ and $G$ might not seem intuitive at first sight, it allows to split the total loan into a covered part $g$ for which the bank charges the "risk-free" interest rate $\bar{R}$ and an uncovered part $L-g$ for which the risk-adjusted interest rate $R^{B}$ is demanded.

${ }^{47}$ Note that the last two components rest on the assumption that the firms' opportunity costs of investment is the same as for banks, that is, they can invest an unlimited amount at an interest rate of $\bar{R}$. Our qualitative results are not sensitive to choosing other rates for the alternative investment, such as a deposit rate that is smaller than the bank-lending rate, or the return to another project that might exceed the risk-free lending rate.
} 
states that coverage cannot exceed the borrowed amount. ${ }^{48}$ To narrow down the number of possible cases of financing modes, it is assumed that whenever the costs of two modes are equal, the firm chooses the one that involves less transactions, i.e., the firm uses internal finance if this is as costly as external finance and it purchases a guarantee only if this strictly lowers the costs of external finance.

Kuhn-Tucker conditions:

$$
\begin{array}{rlrl}
\frac{\partial \pi}{\partial p}=\mu_{1} a q^{\prime}+\mu_{2}(p q)^{\prime} & \Leftrightarrow \quad \lambda(p q)^{\prime}-\bar{R} a q^{\prime}=\mu_{1} a q^{\prime}-\mu_{2}(p q)^{\prime} \\
\frac{\partial \pi}{\partial \ell}=-\mu_{1}+\mu_{2} R^{B}-\mu_{4} \quad \Leftrightarrow \quad \bar{R}-\lambda R^{B} & =-\mu_{1}+\mu_{2} R^{B}-\mu_{4} \\
\frac{\partial \pi}{\partial g}=-\mu_{2}\left[R^{B}(1-\gamma \bar{R})-\bar{R}\right]-\mu_{3}+(1-\gamma \bar{R}) \mu_{4} & \\
\Leftrightarrow \quad \lambda R^{B}(1-\gamma \bar{R})-\lambda \bar{R}=-\mu_{2}\left[R^{B}(1-\gamma \bar{R})-\bar{R}\right]-\mu_{3}+(1-\gamma \bar{R}) \mu_{4} \\
\mu_{1}[\ell+k-(a q+f)] & =0 & \& & \mu_{1} \geq 0 \\
\mu_{2}\left[p q-R^{B}(\ell-(1-\gamma \bar{R}) g)-\bar{R} g\right] & =0 & \& & \mu_{2} \geq 0 \\
\mu_{3} g & =0 & \& & \mu_{3} \geq 0 \\
\mu_{4}[\ell-(1-\gamma \bar{R}) g] & =0 & \& & \mu_{4} \geq 0
\end{array}
$$

Here, $\mu_{i}$ for $i=1, \ldots, 4$ are Kuhn-Tucker multipliers and a prime indicates the partial derivative with respect to $p$.

\section{C.1 Optimal financing and pricing decisions}

Consider first the optimal choice of $g, g^{*}$, given the optimal amount of the loan $\ell^{*}$. Suppose $0<\ell^{*}<\ell^{\max }$ where $\ell^{\max }$ is the maximum loan size determined by the borrowing constraint. For $\mu_{1} \geq 0 ; \mu_{2} \geq 0$, the firm will chose (i) no coverage if $R^{G} \geq R^{B}$ and (ii) full coverage if $R^{G}<R^{B}$.

Proof i) By contradiction. Suppose $R^{G}>R^{B}$ and $g^{*}>0 . R^{G}>R^{B} \Leftrightarrow \frac{\bar{R}}{1-\bar{R} \gamma}>$ $R^{B}$. Since $\ell^{*}>0$, Eq. C.11 implies $\mu_{3}=0$. Equation C.8 implies $\mu_{4}(1-$ $\gamma \bar{R})=\left(\lambda+\mu_{2}\right)\left[R^{B}(1-\gamma \bar{R})-\bar{R}\right]<0$ and Eq. C.12 implies: $\mu_{4} \geq 0$. A contradiction.

ii) By contradiction. Suppose $R^{G}<R^{B}$ and $g^{*}=0 . R^{G}>R^{B} \Leftrightarrow R^{B}(1-$ $\bar{R} \gamma)>\bar{R}$. Since $g^{*}=0$, Eq. C.12 implies $\mu_{4}=0$. Equation C.8 implies $\mu_{3}=\left(\lambda+\mu_{2}\right)\left[\bar{R}-R^{B}(1-\gamma \bar{R})\right]<0$ and Eq. C.11 implies $\mu_{3} \geq 0$. A contradiction.

By assumption, the firm covers nothing in the knife-edge case $R^{G}=R^{B}$.

\footnotetext{
${ }^{48}$ This assumption simplifies the maximization problem. It will become clear below that it is innocuous, since a necessary condition for the risk-neutral firm to buy a guarantee for any reasons other than to lower the cost of the loan, is that the guarantee premium be actuarially favorable. Under those conditions, however, it is always profitable to also take out the maximum loan.
} 
If $\ell^{*}=0, g^{*}=0$ by definition. Hence, in our earlier notation, $o^{*}=B$ if $R^{G} \geq R^{B}$ and $o^{*}=G$ if $R^{G}<R^{B}$. Importantly, the decision about coverage is independent of the choice of $p^{*}$, given $\ell^{*}$. Hence, we can consider the choice of $\ell^{*}$ and $p^{*}$, taking as given the choice of $o^{*}$. To characterize the set of solutions, it is helpful to define a threshold output level $\bar{q}$, denoting the maximum quantity the firm could produce without relying on external finance, that is, the quantity that solves the financing constraint (C.2) for $\ell=0$ :

$$
k-a \bar{q}-f=0 \quad \Leftrightarrow \quad \bar{q}=\frac{k-f}{a}
$$

We obtain four possible optimal pricing and borrowing strategies, for a given $o^{*} \in(B, G)$, which we label cases (1)-(4). The firm's choice among these strategies depends on exogenous parameters, most importantly the costs of external finance and the firm's productivity relative to its stock of liquid funds.

If external finance is cheaper than internal finance, then there is only one optimal decision as regards the choice of $\ell^{*}$ and $p^{*}$, independent of the other parameters. We label this Case 1.

Case $1\left(\mu_{1}=0, \mu_{2} \geq 0\right)$ : If $\lambda R^{o *}<\bar{R}$, the firm borrows the maximum amount given by the borrowing constraint (C.3).

Proof that $\ell^{*}=\ell^{\text {max }}$ if $\lambda R^{o *}<\bar{R}$. By contradiction. Suppose $\lambda R^{B}<\bar{R}$ and $\ell^{*}<$ $\ell^{\max }$. Then, Eq. C.10 implies $\mu_{2}=0$ and Eq. C.7 implies $\mu_{1}+\mu_{4}-\lambda R^{B}+\bar{R}=0$. Since $\mu_{1} \geq 0$ and $\mu_{4} \geq 0$, this implies $\lambda R^{B} \geq \bar{R}$. A contradiction. Suppose now that $\lambda R^{G}<\bar{R}$ and $\ell^{*}<\ell^{\max }$. Then, Eq. C.10 implies $\mu_{2}=0$. Equations C.7 and C.8 imply $\mu_{1}+\frac{\mu_{3}}{1-\gamma \bar{R}}+\bar{R}-\lambda R^{G}=0$, and since $\mu_{1} \geq 0$ and $\mu_{3} \geq 0$ this implies $\lambda R^{G} \geq \bar{R}$. A contradiction.

This result implies that we can ignore the possibility that the firm buys a guarantee for an amount that exceeds the size of the loan, which might be profitable if the premium is actuarially favorable, that is, $\bar{R} \gamma<1-\lambda$. Under this condition, however, external finance is also cheaper than internal finance and hence, the firm will always take out the maximum (project-specific) loan, which is also equal to the maximum amount of coverage. As to the coverage decision, we can use the result derived above. Taking out the full loan with coverage is profitable if $R^{B}>R^{G}$, since $\bar{R} \gamma<1-$ $\lambda \Leftrightarrow \lambda R^{G}<\bar{R}$. Then, $\mu_{3}=0$. Conducting the business with pure bank finance is preferred if $R^{B} \leq R^{G}$. Then, $\mu_{4}=0$. The optimal price $p^{*}$ is determined by Eq. C.6 and, for either choice of financing mode $o^{*} \in(B, G)$, results as

$$
p_{1}^{*}=\frac{R^{o *} a}{\theta} .
$$

Maximum (expected) profits are then

$$
\pi_{1}^{*}=\frac{\bar{R}}{\varepsilon R^{o *}}\left(\frac{R^{o *} a}{\theta}\right)^{1-\varepsilon} A-\bar{R} f .
$$


If external finance is more expensive than internal finance, the firm either borrows nothing or the minimum amount given by the financing constraint (C.2).

Proof We first show that for $\lambda R^{o *}>\bar{R}$ and $\ell^{*} \geq 0$ the borrowing constraint cannot be binding, because either (i) firms would make non-negative profits if it was binding or (ii) find it optimal anyway to decrease the size of the loan. Hence, $\mu_{2}=0$. Then, we show (iii) that if the financing constraint is also not binding $\left(\mu_{1}=0\right), \ell^{*}$ must be zero. It follows that for $\ell^{*}>0$ the financing constraint must be binding. (i) Suppose both constraints (C.2) and (C.3) are binding. Then, expected profits (C.1) become $-\bar{R} k$. (ii) By contradiction. Suppose the borrowing constraint (C.3) is binding, but the financing constraint is not. Then, Eq. C.10 implies $\mu_{2} \geq 0$. If $\lambda R^{G} \geq \lambda R^{B}>\bar{R}$, Eq. C.12 implies $\mu_{4}=0$ and Eq. C.7 implies $\mu_{2}=\bar{R}-\lambda R^{B}<0$. A contradiction. If $\lambda R^{B} \geq \lambda R^{G}>\bar{R}$, Eq. C.11 implies $\mu_{3}=0$ and Eqs. C.7 and C.8 imply $\mu_{2}=$ $1-\lambda-\gamma \bar{R}<0$. A contradiction. (iii) If $\mu_{1}=0$ and $\mu_{2}=0$, Eq. C.7 implies that $\mu_{4}>0$. Hence, $\ell^{*}=0$.

As regards the optimal price (output), we can distinguish three cases. Which one the firm chooses depends on the its size (productivity level) relative to the amount of liquid funds.

Case $2\left(\mu_{1}=0 ; \mu_{2}=0\right): \ell^{*}=0$. In this case, the firm produces the first best quantity that sets $\frac{\partial \pi}{\partial p}=0$ without using external finance, that is, $q^{*} \leq \bar{q}$. This is the case where the firm is relatively unproductive so that its first-best quantity is small. The financing constraint is not binding and $p^{*}$ is determined by Eq. C.6:

$$
p_{2}^{*}=\frac{\bar{R} a}{\lambda \theta} .
$$

Optimal profits are derived from Eq. C.1 and result as

$$
\pi_{2}^{*}=\frac{\lambda}{\varepsilon}\left(\frac{\bar{R} a}{\lambda \theta}\right)^{1-\varepsilon} A-\bar{R} f .
$$

Case $3\left(\mu_{1} \geq 0 ; \mu_{2}=0\right)$ : The firm is of intermediate size and chooses its optimal price (quantity) such as to avoid borrowing external funds; hence, $\ell^{*}=0$ and $q^{*}=\bar{q}$ is given by the financing constraint. $p^{*}$ is derived from Eq. 1 as

$$
p_{3}^{*}=\bar{q}^{-\frac{1}{\varepsilon}} A^{\frac{1}{\varepsilon}},
$$

maximum profits according to Eq. C.1 result as

$$
\pi_{3}^{*}=\lambda\left(\frac{k-f}{a}\right)^{1-\frac{1}{\varepsilon}} A^{\frac{1}{\varepsilon}}-\bar{R} k .
$$


Case $4\left(\mu_{1} \geq 0 ; \mu_{2}=0\right.$ :) The firm is large and takes out a loan $\ell^{*}>0$ that is determined by the financing constraint in Eq. C.2. ${ }^{49}$ With the financing constraint binding, the optimal loan size $\ell^{*}$ is determined given $p^{*}$, which in turn follows from Eq. C.7 with $\mu_{1}=\lambda R^{B}-\bar{R}$ if $o^{*}=B$ or $\mu_{1}=\frac{\bar{R}}{1-\gamma \bar{R}}-\bar{R}>0$ if $o^{*}=G$ and results as

$$
p_{4}^{*}=\frac{R^{o *} a}{\theta} .
$$

Maximum (expected) profits are then

$$
\pi_{4}^{*}=\frac{\lambda}{\varepsilon}\left(\frac{R^{o *} a}{\theta}\right)^{1-\varepsilon} A-\lambda R^{o *} f+\left(\lambda R^{o *}-\bar{R}\right) k .
$$

\section{C.2 Sorting}

Given a certain $k$, firms sort themselves uniquely into Cases $2-4$ depending on their productivity level. The pricing strategy of Case 2 is only feasible, if the firm is small enough to produce the profit maximizing quantity without relying on external finance in the first place, that is, if $q^{*} \leq q$. The threshold productivity level $\left(1 / a_{2}\right)$ below which firms optimally use the strategy of Case 2 is thus given by $q^{*}=\bar{q}$, that is,

$$
\left(\frac{\bar{R} a_{2}}{\theta \lambda}\right)^{-\varepsilon} A=\frac{k-f}{a_{2}} .
$$

At $1 / a_{2}$, not only quantities but also prices and profits are identical for Cases 2 and 3 . Once firms cross the threshold $1 / a_{2}$, the financing constraint binds. The firm now chooses between producing a smaller than optimal quantity to avoid external finance (Case 3), or producing the profit-maximizing quantity and borrowing the least possible amount needed (Case 4). Since $\pi_{2}^{*}\left[1 / a_{2}\right]=\pi_{3}^{*}\left[1 / a_{2}\right]$ and $\pi_{2}^{*}\left[1 / a_{2}\right]>\pi_{4}^{*}\left[1 / a_{2}\right]$, Case 3 is the preferred financing choice for productivity levels above and sufficiently close to $\left(1 / a_{2}\right)$. Profits in Case 3 , as well as in Case 4 , grow as productivity increases. Whether they eventually intersect depends on the curvature of optimum profits $\pi_{4}^{*}$. The intersection $\pi_{4}^{*}\left(1 / a_{3}\right)=\pi_{3}^{*}\left(1 / a_{3}\right)$ determines $1 / a_{3}$, the productivity level where firms switch from Case 3 to 4 . Since $\pi_{3}^{*}$ is concave in productivity, $\left(1 / a_{3}\right)$ exists if $\pi_{4}^{*}$ is not too concave in productivity $(\varepsilon \geq 2$ is a sufficient condition). Note that the existence of both cutoffs $\left(1 / a_{2}\right)$ and $\left(1 / a_{3}\right)$ depends also on the support of the productivity distribution $\left[a_{H}, a_{L}\right]$ as well as on further parameter constellations: For example, let $k<f$, then pricing strategies of Cases 2 and 3 are infeasible. Also, their relevance depends on the location of the profitability threshold $1 / \bar{a}_{m}^{o *}$ defined by $\pi_{m}^{*}\left[1 / \bar{a}_{m}^{o *}\right]=0$ for $m=1, \ldots, 4$ and $o \in(B, G) .{ }^{50}$

\footnotetext{
${ }^{49}$ In the simplified model in Section 3, we consider a special case of Case 4. Under the assumption that $k<f$, all firms, independently of their productivity level, must use external finance (which we assume is more costly than internal finance) in order to produce a positive quantity.

${ }^{50}$ Note that each possible combination of pricing and financing modes has its own profitability threshold, but once firms have chosen the profit-maximizing mode only the associated profitability threshold is relevant.
} 


\section{C.3 Generalization of Result 1}

Next, we derive the more general version of Result 1, allowing for both higher and lower costs of external relative to internal finance and the case where firms can choose to produce with internal funds only. The results is qualitatively the same, but weaker in the sense that the set of firms that is not affected increases. Firms that do not use external finance are also not affected by changes in its costs. Furthermore, when external finance is less costly than internal finance so that firms want to borrow the maximum amount, the impact of financing costs on exports does not depend on the firm's amount of liquid funds.

Result 1b An increase in the costs of external finance $R^{o \prime}$ with $o^{\prime} \in[B, G]$ weakly increases the productivity threshold and weakly decreases optimal sales. The effect on the profitability threshold is weakly stronger for firms with small liquid funds.

Proof Suppose first that external finance is more costly than internal finance so that firms are in one of Cases 2-4. The costs of external finance affect only firms in Case 4. And, as before, it affects only firms which continue using the same optimal financing mode $o^{\prime} \neq o$, with $o^{\prime}, o \in[B, G]$, or which switch to $o$ but had not been indifferent between the two in the initial situation. For those firms the increase in the costs of external finance of mode $o^{\prime}$ is relevant. $\frac{\partial r_{4}^{*}}{\partial R^{o \prime}}<0$ follows from Eqs. C.16 and 1. Higher $R^{o \prime}$ increases the cutoff $\left(1 / a_{3}\right)$, hence some firms will switch from Case 4 to 3 . This comes with a decrease in the optimal quantity, which is now restricted to what can be produced without external finance. $\frac{\partial\left(1 / a_{3}\right)}{\partial R^{\prime \prime}}>0$ follows from $\pi_{4}^{*}\left(1 / a_{3}\right)=\pi_{3}^{*}\left(1 / a_{3}\right)$ as given in Eqs. C.17 and C.15, and $\frac{\partial \pi_{3}^{*}}{\partial R^{o \prime}}=0, \frac{\partial \pi_{4}^{*}}{\partial R^{o \prime}}<0$ and $\frac{\partial \pi_{4}^{*}}{\partial\left(1 / a_{3}\right)}>\frac{\partial \pi_{3}^{*}}{\partial\left(1 / a_{3}\right)}>0$. Firms that switch from Case 4 to 3 produce smaller quantities than before. This follows from the fact that for $1 / a \geq 1 / a_{3}$, where $\pi_{4}^{*} \geq \pi_{3}^{*}$, the firms that use external finance (Case 4) must have higher sales because their marginal costs are higher. The increase in the profitability threshold $\frac{\partial\left(1 / \bar{a}_{4}^{o \prime}\right)}{\partial R^{\prime \prime}}>0$ follows from $\pi_{4}^{*}\left(1 / \bar{a}_{4}^{o \prime}\right)=0$ as given by Eq. C.17, $\frac{\pi_{4}^{*}}{\partial\left(1 / \bar{a}_{4}^{o \prime}\right)}>0$ and $\frac{\partial \pi_{4}^{*}}{\partial R^{o \prime}}<0$. Furthermore, $\frac{\partial^{2} \pi_{4}^{*}}{\partial R^{o \prime} \partial k}>0$ implies $\frac{\partial^{2}\left(1 / \bar{a}_{4}^{o \prime}\right)}{\partial R^{o \prime} \partial k}<0$, that is, the increase in the profitability threshold is stronger if $k$ is small.

Suppose now that external finance is cheaper than internal finance so that all firms are in Case 1. The increase in $R^{o}$ leads to lower sales and a higher profitability threshold. However, the change in the profitability threshold does not depend on $k$, sinces $k$ does not impact the amount of borrowing in this case. If the costs of external finance increase sufficiently strongly, internal finance becomes cheaper at some point so that firms move into one of the Cases 2-4. This will come with a decrease in optimal sales as well. The decrease in sales for firms who stay in Case 1, $\frac{\partial r_{1}^{*}}{\partial R^{o \prime}}<0$, follows from Eqs. C.13 and 1, and the increase in the profitability threshold $\frac{\partial\left(1 / a_{1}^{o \prime}\right)}{\partial R^{o \prime}}>0$ follows from $\pi_{1}^{*}\left(1 / \bar{a}_{1}^{o \prime}\right)=0$ as given by Eq. C.14, and $\frac{\pi_{1}^{*}}{\partial\left(1 / \bar{a}_{1}^{o \prime}\right)}>0$ and $\frac{\partial \pi_{1}^{*}}{\partial R^{o \prime}}<0$. It is straightforward to show that sales decrease when firms switch from 
Case 1 into 2 or 4, since optimal sales decrease in the (opportunity) costs of finance. Furthermore, since sales in Case 3 are smaller than first-best because the quantity is constrained by the amount of firms' liquid funds, they must also decrease for a firm that switches from Case 1 (first-best) to 3.

\section{References}

Ai C, Norton EC (2003) Interaction Terms in Logit and Probit Models. Econ Lett 80(1):123-129

Allen F, Gale D (1998) Optimal financial crises. J Financ 53(4):1245-1284

Amiti M, Weinstein D (2011) Exports and financial shocks. Q J Econ 126(4):1841-1877

Auboin M, Engemann M (2014) Testing the trade credit and trade link: Evidence from data on export credit insurance. Rev World Econ 150(4):715-743

Badinger H, Url T (2013) Export Credit Guarantees and Export Performance: Evidence from Austrian Firm-level Data. World Econ 36:1115-1130

Chamberlain G (1980) Analysis of covariance with qualitative data. Rev Econ Stud 47(1):225-238

Chor D, Manova K (2012) Off the cliff and back? credit conditions and international trade during the global financial crisis. J Int Econ 87:117-133

Dewit G (2001) Intervention in risky export markets: Insurance, Strategic Action or Aid? Europ J Polit Econ 17(3):575-592

Diamond DW, Dybvig PH (1983) Bank runs, deposit insurance, and liquidity. J Polit Econ 91(3):401419

Egger P, Url T (2006) Public export credit guarantees and foreign trade structure: Evidence from austria. World Econ 29(4):399-418

Feenstra RC, Li Z, Yu M (2014) Exports and credit constraints under incomplete information: Theory and evidence from china. Rev Econ Stat 96(4):729-744

Felbermayr G, Heiland I, Yalcin E (2012) Mitigating Liquidity Constraints: Public Export Credit Guarantees in Germany. CESifo Working Paper Series 3908, CESifo Group Munich

Felbermayr G, Yalcin E (2013) Export credit guarantees and export performance: an empirical analysis for germany. World Econ 36(8):967-999

Gordy MB, Howells B (2006) Procyclicality in Basel II: Can We Treat the Disease Without Killing the Patient? Journal of Financial Intermediation

Greenaway D, Guariglia A, Kneller R (2007) Financial factors and exporting decisions. J Int Econ 73(2):377-395

Greene W (2010) Testing hypotheses about interaction terms in nonlinear models. Econ Lett 107(2):291296

Greene W, Henscher D (2010) Modelling ordered choices: a primer. Cambridge University Press, New York

Janda K, Michalikova E, Skuhrovec J (2013) Credit support for export: Robust evidence from the czech republic. World Econ 36(12):1588-1610

Kashyap AK, Rajan R, Stein JC (2002) Banks as Liquidity Providers: An Explanation for the Coexistence of Lending and Deposit-taking. J Financ 57(1):33-73

Manova K (2013) Credit constraints, heterogeneous firms, and international trade. Rev Econ Stud 80(2):711-744

Manova K, Wei S-J, Zhang Z (2015) Firm exports and multinational activity under credit constraints. Rev Econ Stat 97(3):574-588

Matsuyama K (2008) Aggregate Implications of Credit Market Imperfections. In: NBER Macroeconomics Annual 2007, Volume 22, NBER Chapters. National Bureau of Economic Research, Inc., pp 1-60

Mayer C (1988) New issues in corporate finance. Eur Econ Rev 32(5):1167-1183

Melitz MJ (2003) The Impact of Trade on Intra-industry Reallocations and Aggregate Industry Productivity. Econometrica 71(6): 1695-1725

Merton RC (1977) An analytic derivation of the cost of deposit insurance and loan guarantees: an application of modern option pricing theory. J Bank Financ 1(1):3-11

Minetti R, Zhu SC (2011) Credit constraints and firm export: Microeconomic evidence from italy. J Int Econ 83(2):109-125 
Moser C, Nestmann T, Wedow M (2008) Political Risk and Export Promotion: Evidence from germany. World Econ 31(6):781-803

Mundlak Y (1978) On the pooling of time series and cross section data. Econometrica 46(1):69-85

Muûls M (2008) Exporters and Credit Constraints. A Firm-level Approach. Working Paper Research 139, National Bank of Belgium

Schertler A, Buch C, Westernhagen N (2006) Heterogeneity in lending and sectoral growth: Evidence from german Bank-Level data. IEEP 3(1):43-72

Sharpe SA (1990) Asymmetric information, bank lending and implicit contracts: a stylized model of customer relationships. J Financ 45(4):1069-1087

Wooldridge JM (2002) Econometric analysis of cross section and panel data. The MIT Press, Cambridge

Publisher's note Springer Nature remains neutral with regard to jurisdictional claims in published maps and institutional affiliations. 